

\title{
A NIOBIUM-TIN DEALS TOROIDAL MAGNET SYSTEM FOR A HIGH FIELD IGNITION TEST REACTOR
}

J. Powell, S. Hsieh, P. Bezler, D. Gardner, M. Reich, C. Laverick,

M. Finkelman, T. Brown, J. Bundy, R. Herberman, and C.H. von Keszycki

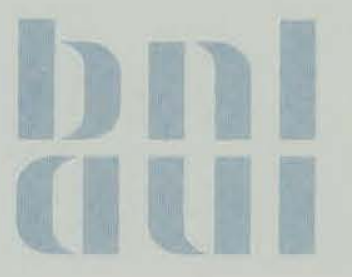

December 1977

\section{BROOKHAVEN NATIONAL LABORATORY ASSOCIATED UNIVERSITIES, INC. UNDER CONTRACT NO. EY-76-C-02-0016 WITH THE UNITED STATES DEPARTMENT OF ENERGY}




\section{DISCLAIMER}

This report was prepared as an account of work sponsored by an agency of the United States Government. Neither the United States Government nor any agency Thereof, nor any of their employees, makes any warranty, express or implied, or assumes any legal liability or responsibility for the accuracy, completeness, or usefulness of any information, apparatus, product, or process disclosed, or represents that its use would not infringe privately owned rights. Reference herein to any specific commercial product, process, or service by trade name, trademark, manufacturer, or otherwise does not necessarily constitute or imply its endorsement, recommendation, or favoring by the United States Government or any agency thereof. The views and opinions of authors expressed herein do not necessarily state or reflect those of the United States Government or any agency thereof. 


\section{DISCLAIMER}

Portions of this document may be illegible in electronic image products. Images are produced from the best available original document. 
BNL 50802

UC-20

(Magnetic Fusion Energy - TID-4500)

\title{
A NIOBIUM-IIN DEALS TOROIDAL MAGNET SYSTEM FOR A HIGH FIELD IGNITION TEST REACTOR
}

\author{
J. Powell, S. Hsieh, P. Bezler, D. Gardner, and M. Reich \\ Brookhaven National Laboratory \\ C. Laverick, Consultant to Brookhaven National Laboratory \\ M. Finkelman, T. Brown, J. Bundy, R. Herberman, C.H. von Keszycki \\ Grumman Aerospace Corporation \\ Bethpage, New York
}

December 1977

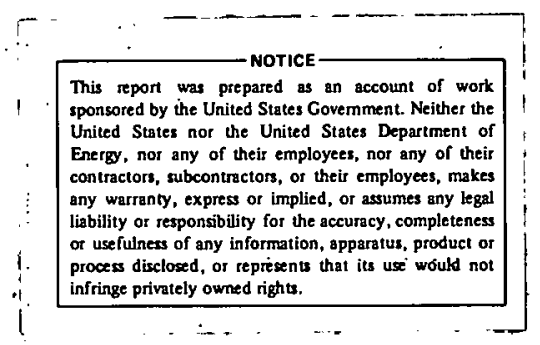

BROOKHAVEN NATIONAL LABORATORY UPTON, NEW YORK 11973 


\section{NOTI C E}

This report was prepared as an account of work sponsored by the United States Government. Neither the United States nor the United States Department of Energy (DOE), nor any of their employees, nor any of their contractors, subcontractors, or their employees, makes any warranty, express or implied, or assumes any legal liability or responsibility for the accuracy, completeness or usefulness of any information, apparatus, product or process disclosed, or represents that its use would not infringe privately owned rights.

Printed in the United States of America Available from

National Technical Information Service U.S. Department of Commerce

5285 Port Royal Road

Springfield, VA 22161

Price: Printed Ciopy $\$ 5.25$; Microfiche $\$ 3.00$

March 1978 


\section{ABSTRACT}

Using a High Field Ignition Test Reactor application based on the Tokamak magnetic confinement approach, a three-month study effort focused on developing a feasible demountable DEALS toroidal magnet system design which would simplify the construction of the magnet and reactor, as well as facilitate future maintenance during long-term operation. This target was successfully achieved. The overall DEALS design is described, together with the basic reactor parameters. Detalled stress analyses for the support structure are given, together with magnet and conductor specifications. Preliminary electrical contact tests relating to joint design are also discussed. 


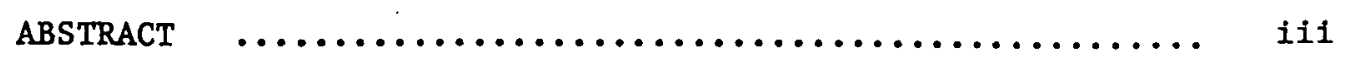

TABLE OF CONTENTS $\ldots \ldots \ldots \ldots \ldots \ldots \ldots \ldots \ldots \ldots \ldots$ iv

LIST OF FIGURES $\ldots \ldots \ldots \ldots \ldots \ldots \ldots \ldots \ldots \ldots \ldots \ldots \ldots \ldots \ldots$

LIST OF TABLES $\quad \ldots \ldots \ldots \ldots \ldots \ldots \ldots \ldots \ldots \ldots \ldots \ldots \ldots \ldots \ldots \ldots \ldots \ldots \ldots \ldots$

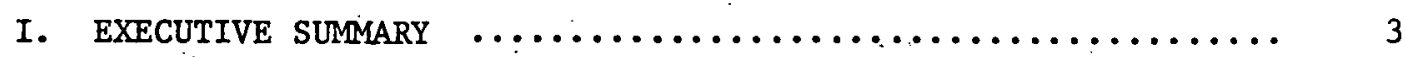

II. INTRODUCTION $\ldots \ldots \ldots \ldots \ldots \ldots \ldots \ldots \ldots \ldots \ldots \ldots \ldots \ldots \ldots \ldots .10$

III. STUDY PLAN AND OBJECTIVES $\ldots \ldots \ldots \ldots \ldots \ldots \ldots \ldots \ldots \ldots \ldots \ldots \ldots$

IV. SUPPORT STRUCTURE DESIGN AND ANALYSIS $\ldots \ldots \ldots \ldots \ldots \ldots \ldots \ldots .16$

V. REACTOR ASSEMBLY AND ACCESS $\ldots \ldots \ldots \ldots \ldots \ldots \ldots \ldots \ldots \ldots \ldots, 32$

VI. TOROIDAL FIELd COIL ANALYSIS AND DESIGN $\ldots \ldots \ldots \ldots \ldots \ldots \ldots .40$

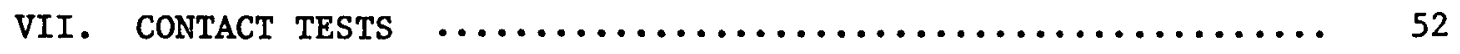

viII. ACKNOWLEDGMENTS $\ldots \ldots \ldots \ldots \ldots \ldots \ldots \ldots \ldots \ldots \ldots \ldots \ldots \ldots \ldots \ldots \ldots$ 


\section{LIST OF FIGURES}

Fig. 1 Assembly Sequence for DEALS System $\ldots \ldots \ldots \ldots \ldots \ldots \ldots \ldots \ldots \ldots$

Fig. 2 Vacuum Vessel Installation $\ldots \ldots \ldots \ldots \ldots \ldots \ldots \ldots \ldots \ldots \ldots \ldots$

Fig. 3 . Bore of Superconducting $\mathrm{TF}$ Colls $\ldots \ldots \ldots \ldots \ldots \ldots \ldots \ldots \ldots \ldots$

Fig. 4 In Plane Structural Support Options $\ldots \ldots \ldots \ldots \ldots \ldots \ldots \ldots \ldots \ldots$

Fig. $5 \quad$ Coll Stress Summary $\ldots \ldots \ldots \ldots \ldots \ldots \ldots \ldots \ldots \ldots \ldots \ldots \ldots \ldots \ldots$

Fig. $6 \quad$ Coll Cooling Schematic $\ldots \ldots \ldots \ldots \ldots \ldots \ldots \ldots \ldots \ldots \ldots \ldots \ldots$

Fig. 7 Conductor Cooling Detail $\ldots \ldots \ldots \ldots \ldots \ldots \ldots \ldots \ldots \ldots \ldots$

Fig. 8 Clearance Take Up/Compression Options $\ldots \ldots \ldots \ldots \ldots \ldots \ldots \ldots \ldots$.

Fig. 9 Magnet Study Plan Summary $\ldots \ldots \ldots \ldots \ldots \ldots \ldots \ldots \ldots \ldots \ldots \ldots$

Fig. 10 Envelope Requirements Developed for DEALS Post TFTR Upgrade ... 16

F1g. 11 . In Plane Structural Support Options $\ldots \ldots \ldots \ldots \ldots \ldots \ldots \ldots \ldots \ldots$

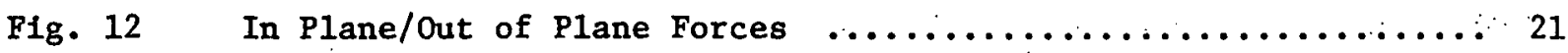

Fig. 13 Baseline Configuration - DEALS Type Post-TFTR Upgrade ........ 22

F1g. 14 Baseline Conflguration - Top View $\ldots \ldots \ldots \ldots \ldots \ldots \ldots \ldots \ldots \ldots$

Fig. 15 Finite Element - In Plane Loading $\left(10^{6} 1 \mathrm{~b}\right) \ldots \ldots \ldots \ldots \ldots \ldots$

Fig. 16. Finite Element Model - Out of Plane Loading $\left(10^{6}\right.$ 1b) ....... 25

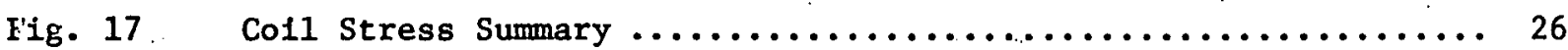

Fig. 18 Manufacturing Procedure for a Typical Structural Member ....... 27

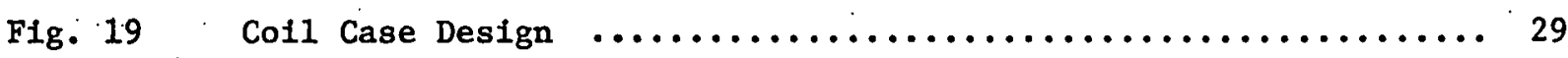

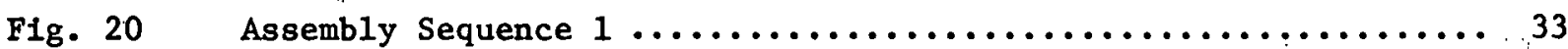

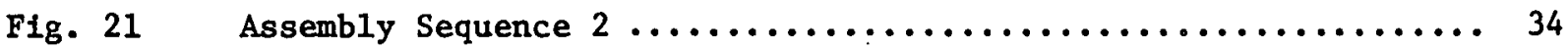

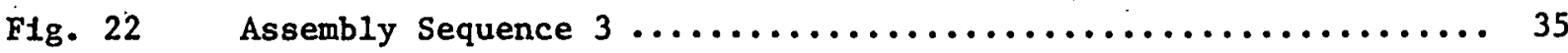

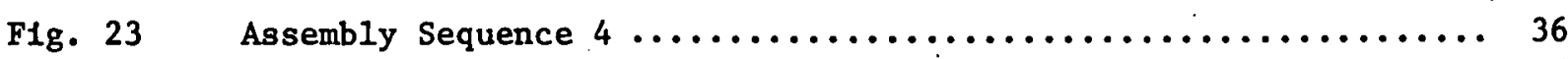

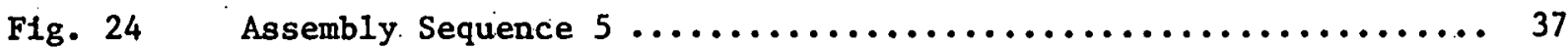




\section{LIST OF FIGURES (continued)}

P1g. $25 \quad$ Page

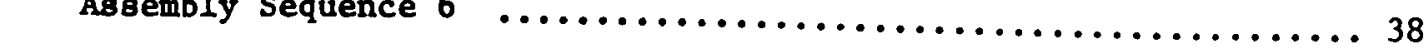

Fig. 26 Total Assembly Sequence 1 to $6 \ldots \ldots \ldots \ldots \ldots \ldots \ldots \ldots \ldots$

F1g. 27 DEALS HFITR Conductor Concept $\ldots \ldots \ldots \ldots \ldots \ldots \ldots \ldots \ldots \ldots \ldots \ldots \ldots \ldots \ldots \ldots \ldots \ldots$

Fig. $28 \quad$ Coll and Conductor Design Showing Detalls of Conductor Assembly Ceramic Inter-Turn Insulators and Pool Boiling Liquid Concept $\ldots \ldots \ldots \ldots \ldots \ldots \ldots \ldots \ldots \ldots \ldots \ldots \ldots \ldots \ldots \ldots \ldots$

F1g. 29 Comparison of Pool and Forced Flow Cooling Capability ........ 44

F1g. $30 \quad$ A Fall Safe Power Lead for Superconducting Colls ..........48

F1g. 31 . A Los Alamos Scientific Laboratory Pressure Contact Joint ..... 48

F1g. 32 Contact Heating vs Copper Resistivity and Effective Contact

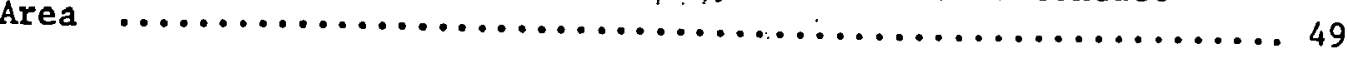

F1g. 33 Conceptual Joint Design's Clearance Take Up Compression Options . 50

F1g. 34 Test R1g for Simulating Movable Contacts .............. 53

Fig. 35 Arrangement for Rough Scoping Tests of Contacts in Liquid

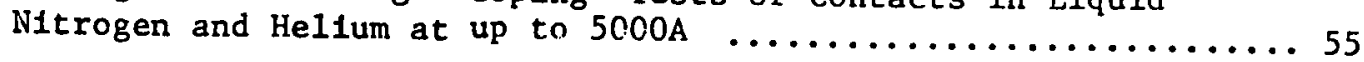

Fig. 36 Test Installation for Scoping Tests on Contacts at Liquid

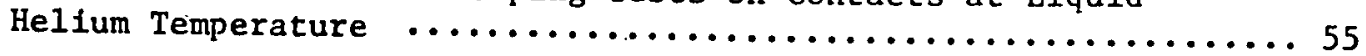




\section{LIST OF TABLES}

Page

Table 1 Reactor Parameter (PPPL)

Table $\cdot 2$

Cost/Technology Issues

5

Table 3 Coil Design Features

7

Table 4 HFITR Coil Design Parameters

Table 5 Major TFTR Upgrade Parameters as LEveloped in Princeton Plasma Physics Laboratory

Table 6

Support Structure Material Summary

Table 7

HFITR Coil Design Parameters

Table 8 Equations Used to Derive the Forced Flow Supercritical Helium Cooling Characteristic Curves of Fig. 29 

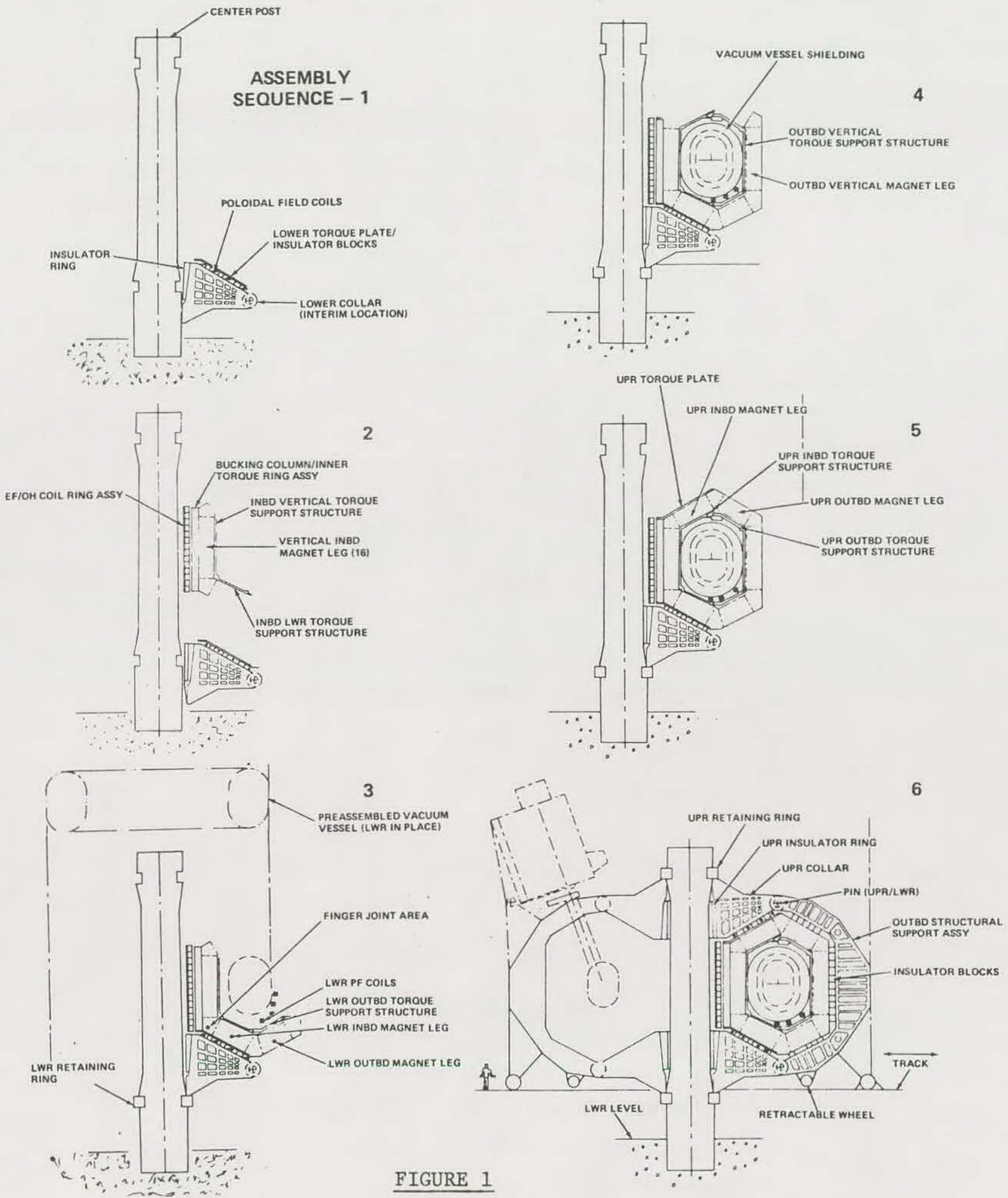

Assemb1y Sequence for DEALS System: This shows how the system could be assembled or dismantled, starting with the outer tension post (Step 1) and moving through installation of inboard magnet legs and torque structure (2), vacuum chambers ( 3 ), the rest of the magnet ( 4 and 5 ), and finally the outboard structural support (6). 


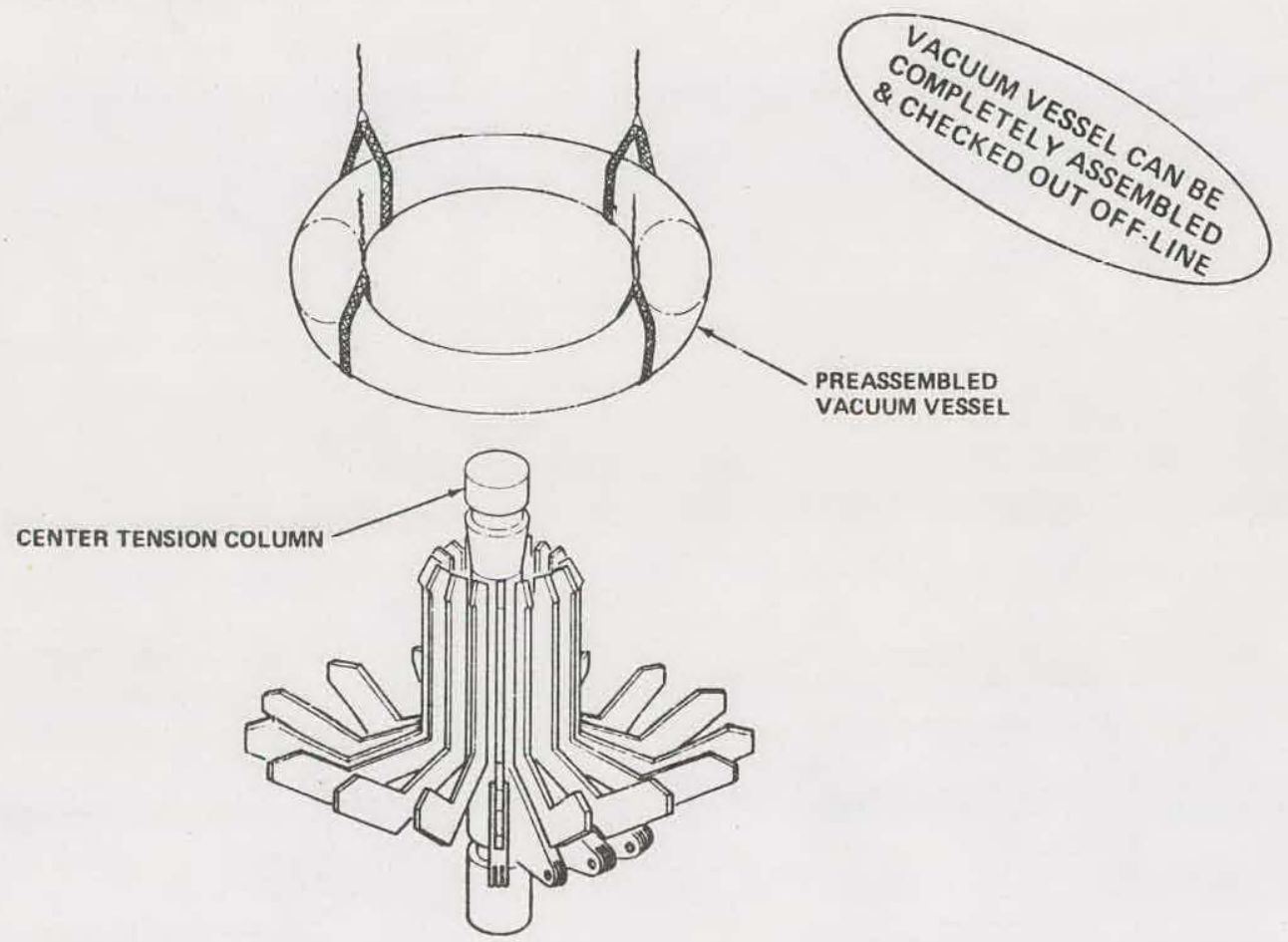

FIG. 2, VACUUM VESSEL INSTALLATION

\section{CONCLUSIONS}

- PASSive SupPort StRucture can be designed

- ACCESSIBILITY to REACTOR IS NOt IMPAIRED

- tF MAgNet demountability is FeAsible

- all Reactor components are removable

- Structural design faVors MOVABLE PRESSURE JoINTS

- JOINT FEASIBILITY NOT YET FIRMLY ESTABLISHED 


\section{EXECUTIVE SUMMARY}

This report describes the results of a three-months study (June to September, 1977), which examined in some detall the feasibility of applying the "Demountable Externally Anchored Low Stress" (DEALS) magnet system to near-term Tokamak type experimental fusion reactors. The study team included staff from Grumman Aerospace Corporation and Brookhaven National Laboratory and additional advice and consultation was given generously by Princetion Plasma Physics Laboratory staff.

In the earlier initial studies of the DEALS concept, the magnet forces were assumed to be supported by a room temperature pre-stressed concrete reactor vessel, through hydraulic actuators'which could compensate for movement due to magnet cool down $(300 \mathrm{~K}$ to $4.2 \mathrm{~K}$ ) and magnetic loads. The present study identified 3 key issues which it examined in some detail: (1) could a satisfactory support system be engineered, (2) could the design permit access to all reactor components if necessary, and (3) could satisfactory joints between successive winding segments of the magnet turns be developed? The first two issues were answered affirmatively. Although the third issue could not be answered definitively, there was considerable optimism, as there seemed to be no fundamental problem in developing the required joints. More experimental engineering work is needed to verify satisfactory joint operation.

In order to focus on a near-term reactor application, an early version of a TFTR upgrade concept from Princeton Plasma Physics Laboratory, designated as HFITR (High Field Ignition Test Reactor) was chosen for the design study. The DEALS baseline conceptual design shown in Figures 1-6 was then developed. It was concluded that a demountable DEALS type magnet system appeared feasible for this application. The room temperature support could be assembled and 
taken apart as needed for access to internal reactor components (see Figures 1 and 2). The principal conclustons are listed in Figure 2.

The reactor study parameters are compared in Table 1 with two other Princeton superconducting Tokamak magnet concepts. The relative bore sizes are shown in Figure 3, together with the Soviet $\mathrm{T}-10 \mathrm{M}$ superconducting magnet concept.

The main cost and technology issues are listed in Table 2, with the DEALS concept for HFITR compared with EPR magnets designed by Oak Ridge and Argonne National Laboratories. It appeared that the DEALS approach required less conductor development but more joint design and testing. There seemed to be no way to compare the manufacturing and construction aspects of a DEALS system with the two more conventional approaches to EPR design since the coils were so different and no reactor integration had been attempted in the other studies. Finally, with regard to reactor operation, it was judged that the demountable magnet should increase reactor avallability and could result in large savings In Iife cycle cost.

Four options were considered in studying the structural suprort system (see Figure 4). The first configuration, a simple rectangular shape was the same as that assumed in earlier studies. The six-sided shape of configuration 2 (Figure 4) was found to be the most promising, since it developed the smallest force distribution under load, for comparable operating conditions, and used the least amount of reinforcement. This configuration should produce the lowest cost reactor system. A detailed stress analysis of the six-sided configuration is summarized in Figure 5. The maximum stresses are compressive, which is particularly important for niobium tin since it should be operated in compression, and the stress magnitudes are within acceptable limits. In practice they could probably be reduced by modffications in design. 
FIG. 3, BORE OF SUPERCONDUCTING TF COILS

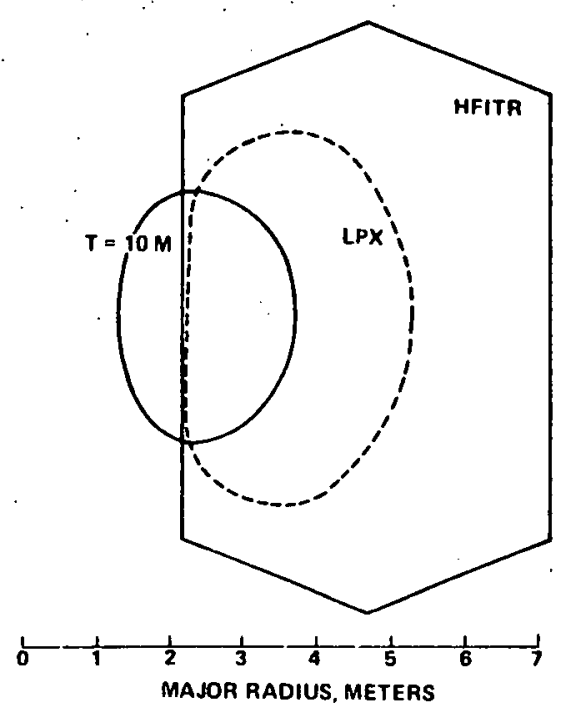

TABLE I, REACTOR PARAMETER (PPPL)

- TF-COIL CONDCUTOH

- tF COIL BORE

- BMAX

- BT (ON AXIS)

- TRITIUM BURNING

\begin{tabular}{|l|}
\hline HFITR \\
(TFTR UPGRADE) \\
\hline $\mathrm{Nb}_{3} \mathrm{Sn}$ \\
$5 \mathrm{M} \times 8 \mathrm{M}$ \\
$12 \mathrm{~T}$ \\
$\sim 7 \mathrm{~T}$ \\
$\mathrm{YES}$ \\
\hline
\end{tabular}

$\underline{\text { LPX }} \quad \underline{E P R}$ $\mathrm{Nb}_{3} \mathrm{Sn} \cdot \mathrm{Nb}_{3} \mathrm{Sn}$

$3 \mathrm{M} \times 5 \mathrm{M} \quad 5 \mathrm{M} \times 8 \mathrm{M}$

$\sim 12 T ?$

$\sim 7 T-7 T$

NO YES

TABLE 2, COST/TECHNOLOGY ISSUES

DEVELOPMENT

- CONDUCTOR DEVELOPMENT SIMPLIFIED

- JOINT DESIGN/TESTING REUUIRED

MANUFACTURING

\begin{tabular}{|l|c|c|c|}
\cline { 2 - 4 } \multicolumn{1}{c|}{ MANUFACTURING } & HFITR & ORNL EPR & ANL EPR \\
\hline SUPERCONDUCTOR & $\mathrm{NG}_{3} \mathrm{Sn}$ & $\mathrm{NbTi} / \mathrm{Nb}_{3} \mathrm{Sn}$ & $\mathrm{NbTi}$ \\
COIL BORE & $5 \mathrm{M} \times 8 \mathrm{M}$ & $7 \mathrm{M} \times 10 \mathrm{M}$ & $8 \mathrm{M} \times 13 \mathrm{M}$ \\
COIL SHAPE & "DEALS" & OVAL & PURE TENSION \\
MAX. FIELD & $12 T$ & $11 \mathrm{~T}$ & $10 T$ \\
COOLING & POOL BOILING & FORCED FLOW & SU3-ICOOLED \\
\hline
\end{tabular}

HOW TO COMPARE? - COILS NOT SIMILAR - NO REACTOR INTEGRATION

OPERATIONS

- DEMOUNTABLE TF MAGNET — INCREASED REACTOR AVAILABILITY

- LARGE LIFE CYCLE COST SAVINGS ARE POSSIBLE 
FIG.4, IN PLANE STRUCTURAL. SUPPORT OPTIONS
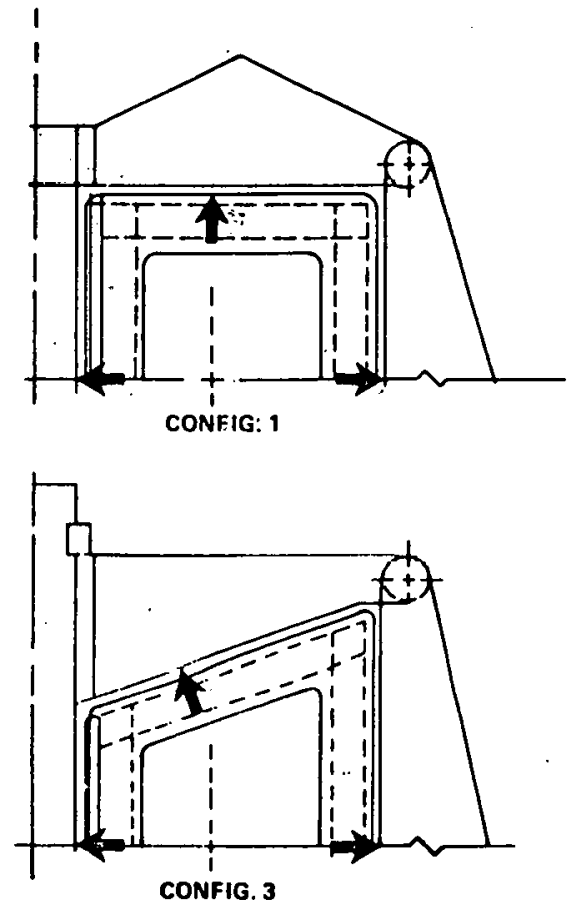

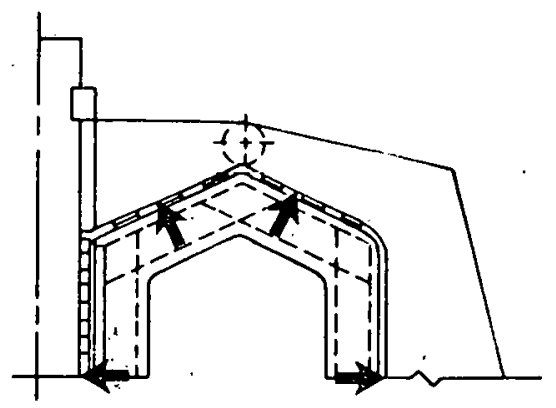

CONFIG. 2

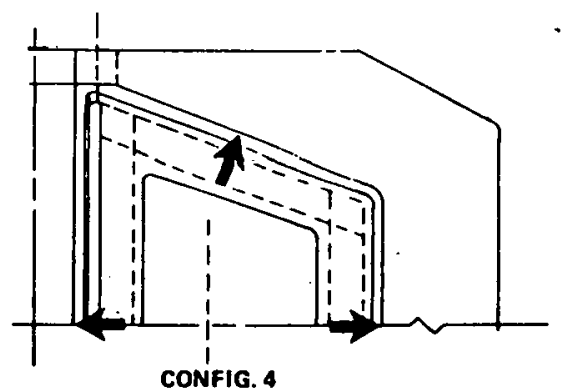

FIG. 5, COIL. STRESS SUMMARY

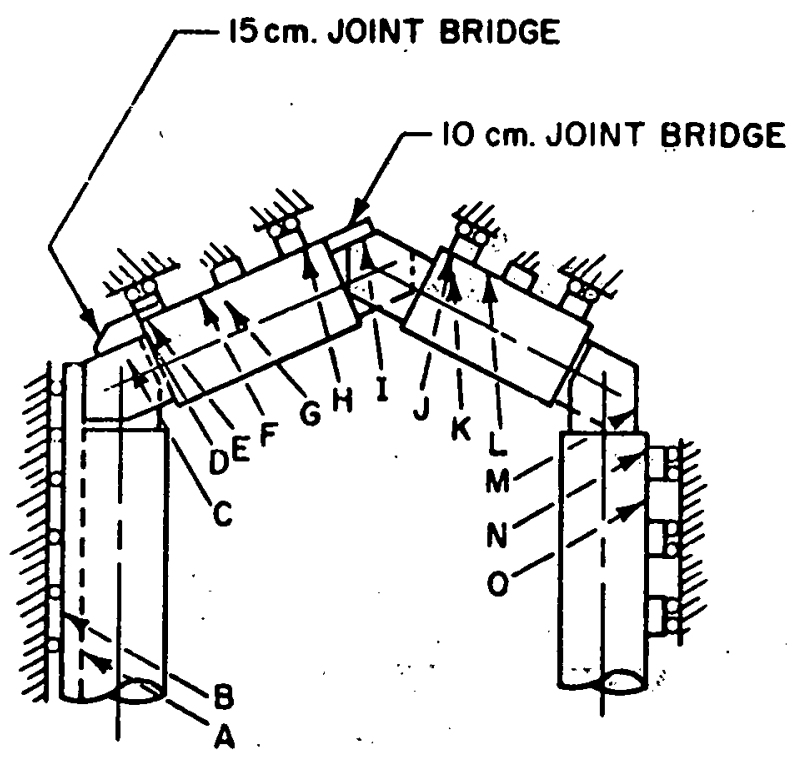

LOCATION MATERIAL STRESS,.pgi

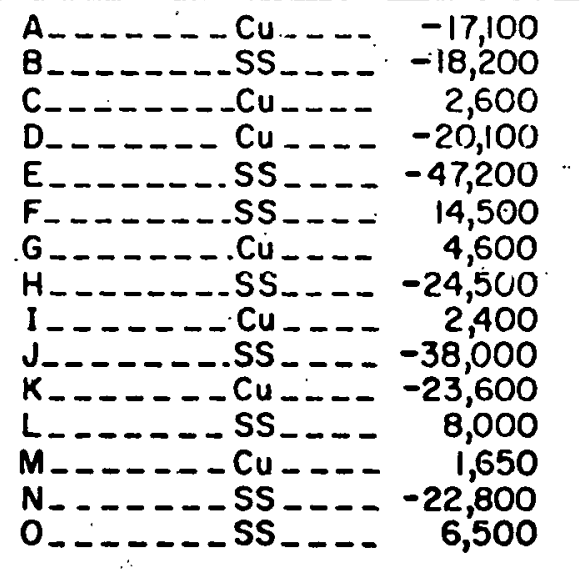




\section{TABLE 3, COIL DESIGN FEATURES}

CONDUCTOR

- BAAIDED $\mathrm{Nb}_{3} \mathrm{~S}_{n}$ IN COPPER PLATES

INSULATORS

- ceramic or organic

CONDUCTOR JOINT

- eXPERIENCE AT LASL

- BNL EXPERIMENTAL PROGRAM

COIL CASE

- STEEL CASE For COIL SUPPort IS ALSO HeLIUM DEWAR

COOLING

- POOL BOILING (CRYOSTATICALLY STABILIZED)

REFRIGERATION POWER

- TOTAL INPUT POWER (ROOM TEMP.) $=1.45$ MW (ROOM TEMP.)

$$
=4.47 \mathrm{KW}\left(A T 5^{\prime \prime} \mathrm{K}\right)
$$

\section{TABLE 4, HFITR COIL DESIGN PARAMETERS}

NO. OF COILS

COIL BORE

COIL CROSS SECTION

CONDUCTOR CROSS SECTION

SC CROSS SECTION (AT $12 \mathrm{~T}$ ) - $\mathrm{Nb}_{3} \mathrm{Sn}$

PEAK·FIELD AT CONDUCTOR (@ $2.64 \mathrm{M}$ )

FIELD AT PLASMA CENTER (@ $4.7 \mathrm{M}$ )

OPERATING CURRENT

TOTAL AMP TURN

AVERAGE CURRENT DENSITY OVER COIL

HEAT TRANSFER COEFFICIENT (ASSUMING

$50 \%$ COOLING SURFACE ON EACH SIDE OF CONDUCTOR)

TOTAL INDUCTANCE

TOTAL STORED ENERGY

REFRIGERATION INPUT POWER REQUIRED

$\cdot$
16

$5 \mathrm{M} \times 8 \mathrm{M}$

$0.85 \mathrm{M} \times 0.567 \mathrm{M}$

$8 \mathrm{~mm} \times 0.8 \mathrm{M}$

$-1.5 \mathrm{~cm}^{2}$

$12 \mathrm{~T}$

$6.8 \mathrm{~T}$

$2 \times 10^{5}$ AMP

$1.6 \times 10^{8}$

$-2140 \mathrm{~A} / \mathrm{cm}^{2}$

$0.38 \mathrm{~W} / \mathrm{cm}^{2}$

$-1 \mathrm{H}$

$2 \times 10^{10} \mathrm{~J}$

1.45 MW (ROOM TEMP)

$4.47 \mathrm{KW}$ (AT 5" K) 
FIG.6, COIL COOLING SCHEMATIC

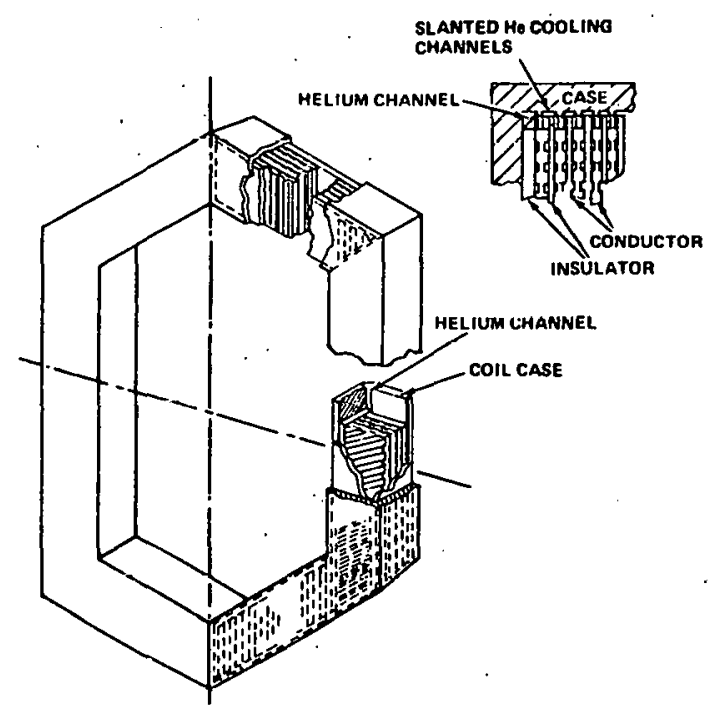

FIG. 7, CONDUCTOR COOLING DETAIL

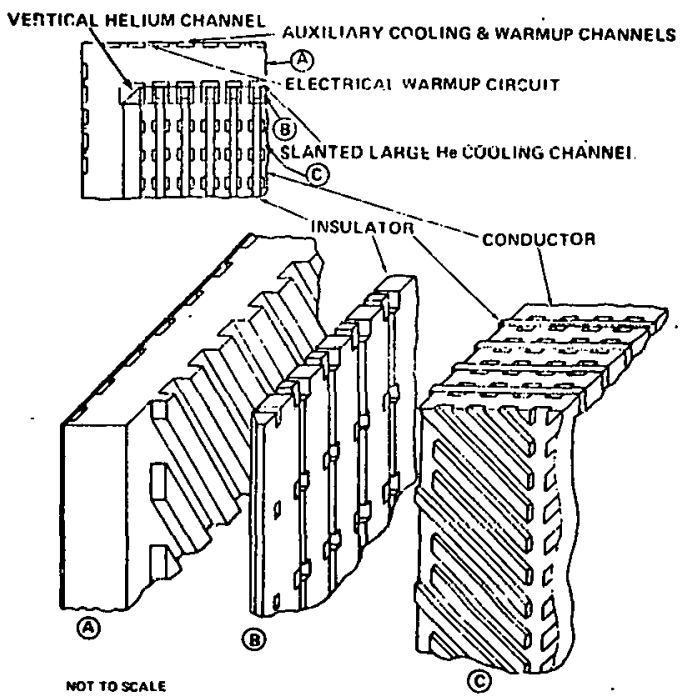

FIG. 8, CLEARANCE TAKE UP/COMPRESSION OPTIONS
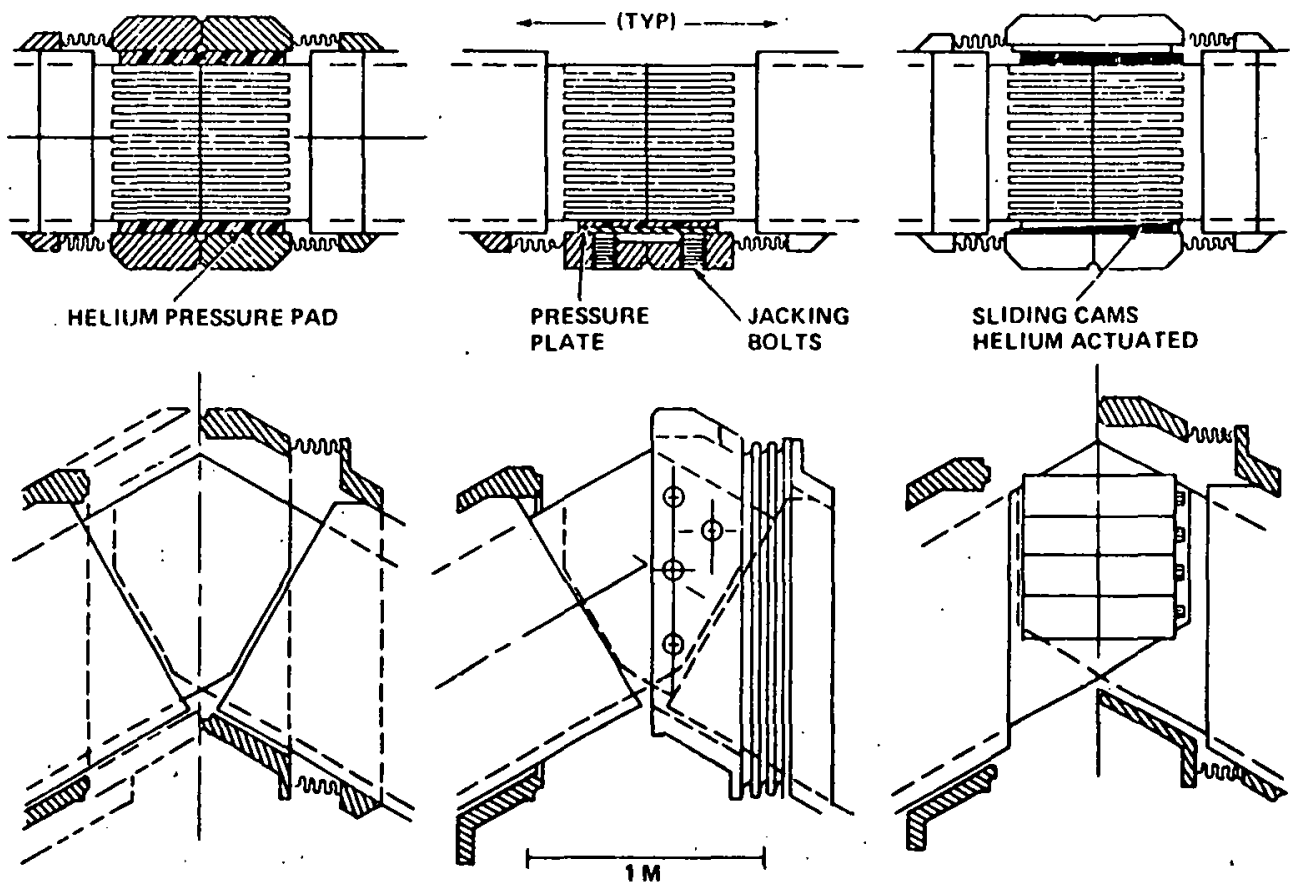
General features of the coll design are listed in Table 3 with the main design parameters for the HFITR system in Table 4. Figures 6 and 7 show the construction of a complete coll section with its 50 turns and cooling arrangement.

A key issue is whether or not satisfactory joints between successive segments of each six-sided turn can be developed. Because of the limited time available, this problem was studied tit not clearly resolved. Some possible mechanical designs are shown in Figure 8. Preliminary scoping electrical contact tests were carried out at 5000A in liquid helium with the help of the BNL ISABELLE Superconductivity Group. A more sophisticated test unit was designed and built to measure changes in contact resistance as a function of such parameters as contact material, contact pressure, contact area and current density. The resolution of joint design questions required more time and effort than could be expended in this study. However, contact conductances of the required order of magnitude were obtained in the rough tests and a large number of ideas as to what sort of test program might be developed were generated as a consequence of the work. It was concluded that satisfactory joints with the desired mechanical and electrical properties could be developed, given the necessary time and support. The problem is one of engineering technology, not of an insuperable, fundamental nature. 


\section{INTRODUCTION}

The "Demountable Externally Anchored Low Stress" (DEALS) magnet system offers an alternative approach to the conventional techniques for winding toroidal superconducting colls. Demountability has been used for the same reasons in some conventional copper coil systems for large Tokamak experiments. It is probably the only feasible way to guarantee acceptable plant availability over the lifetime of a commercial thermonuclear fusion reactor.

In the conventional superconducting $\mathrm{TF}$ magnet system design with continously wound D-shaped constant tension coils, the replacement of a falled coil after construction would be extremely difficult. This would necessitate that the TF coil system should be extremelv reliable over its thirty-year service lifetime. Aside from the limited accessibility for reactor construction and maintenance because of the interlaced reactor components, the replacement of a falled TF coil in this type of reactor construction would involve removing and replacing a large number of highly radioactive, massive components with many major cuts and seals to be made. This would require a very long plant down time, limited plant availability, and lead to large capital losses even it it were technically feaslble. Conventional. superconducting TF coils will have to be orders of magnitude more reliable than has been yet demonstrated in existing superconducting magnets, if availability of the magnet system is to equal or exceed an acceptable limit of $\sim 95 \%$.

The DEALS system gives much greater assurance that realistic on-line capacity factors for commercial reactors can be achieved since reactor 
components inside the magnet system or parts of the magnet system itself can be repaired or replaced:

Practical very high field niobium tin magnet systems of 12 tesla or higher, indicated in many plasma physics studies as being necessary for the development of relatively small ignition reactors, can become an engineering reality with the DEALS concept. This is due to the fact that the strains in the superconductor are much lower than those in more conventionally wound colls of similar performance and are compressive instead of tensile. The DEALS concept is equally applicable to lower field niobium titanium systems; however, at very high fields its advantages become overwhelming.

Simplified mass production of conductor plates and on-site assembly should substantially reduce overall production, and winding costs for the magnet, as well as costs and time for reactor construction.

One Important feature of DEALS is that the results of small scale component tests should be readily applicable to the design of large IEALS magnets, and to a great extent, behavior of the various components can be decoupled. For example, the mechanical and thermal properties of the support pads can be tested on a small. scale and then applied to any DEALS design. Jolnts can. be tested independently from the rest of the coil, so that tests can be carried out more quickly and cheaply. In addition, results with smaller scale joints should be readily extrapolated to large joints if maximum current density and stress levels are not markedly different.

Two scoping studies based on recent Tokamak system concepts incorporating conventionally wound superconducting coils were carried out in early 1977 to assess the possibilities of using demountable coils of rectangular section with an active support system. 1,2 
In these early. studies, the bastc design features incorporated a prestressed concrete reactor vessel (PCRV) which provided the primary structural support for the magnet windings in addition to providing the containment necessary for commerical operation. Relative motion between the windings and support during cool down and magnet energizing was to be eliminated through the use of hydraulic actuators which transmitted the loads from the windings to the support structure. Sets of four conductor plates soldered together to form a rectangular window frame winding with flat ceramic insulators between adjacent turns of the spirally wound coil unit were to be used. Each conductor plate was to consist of a copper sheet of approprlate dimensions to which a fully transposed superconducting brald would be soldcrec to rake up the cryostable superconducting matrix. Finally, the windings were to be immersed in a liquid helium bath at $4.2^{\circ} \mathrm{K}$. It was concluded that demountable superconducting coils were feastble and would offer the possibility of upgrading existing experimental systems as new components, superconductors and stabilizing materials were developed. As a consequence of this early work, BNL was awarded a three month study contract by DMFE to explore; the idea in greater detall. Grumman Aerospace Corporation was selected by BNL as a subcontractor on the basts of its expertise in fusion projects. This report describes the progress of the three month study collaboration and its conclusions. 


\section{STUDY PLAN : AND OBJECTIVES :}

\section{A. Study objectives}

The princtpal objective of this study was to explore the feasibility of the DEALS magnet concept in greater depth than had been possible in the earlier work. Because of time limitations, the study group identified and decided to concentrate on the key issues it considered as absolutely. essential to establish the feasibility of the concept and to not seek an optimum design with respect to system performance and cost.

Such questions as to what cooling mode to adopt or what conductor type or configurations to choose were not considered as crucial to the success or failure of the basic concept even though they are important system design parameters; therefore they were not examined in the detail necessary to optimize the design. As an example, a braided cryostable conductor cooled by pool boiling liquid helium at $4.2^{\circ} \mathrm{K}$ was chosen arbitrarily for the design we explored since it was known that satisfactory magnets could be operated with such a choice of conductior and cooling mode. Full optimization would require more detailed study.

In order to study a realistic option we chose to consider a sfecific design using $\mathrm{Nb}_{3} \mathrm{Sn}$ superconductor operating at a peak field of $12 \mathrm{~T}$ in a toroidal field coil of bore $5 \mathrm{~m} \times 8 \mathrm{~m}$ developing $7 \mathrm{~T}$ at the plasma center and having a blanket and associated tritium burn.

The key questions to be resolved were identified as:

1) Could a fully demountable reactor system be designed and built which would have the necessary ease of assembly and degree of accessibility?

2) Could an external room temperature structure support system for the magnet windings be designed to allow adequate access to the internal reactor components? 
3) Could joints with satisfactory mechanical and electrical characteristics be developed between the successive conductor segments arranged to. form the turns of the winding?

\section{B. Study Plan}

The study approach was to attempt to resolve the key feasibility issues by developing a conceptual design solution for a next generation ignition reactor and to initiate a modest test program which might help determine the type of joint to be used between successive conductor segments in the magnet windings. The reactor chosen was a possible version of a TFTR Upgrade Reactor (May, 1977 definition) which could reach ignition conditions. The major reactor parameters are summarized in Table 5 .

\section{TABLE 5, MAJOR TFTR UPGRADE PARAMETERS AS DEVELOPED IN PRINCETON PL.ASMA PHYSICS LABORATORY}

\begin{tabular}{l|l|}
\hline & \\
- TF-COIL CONOCUTOR \\
- TF COIL BORE & NFTR UPGRADE) \\
\hline - BMAX & $5 \mathrm{M} \times 8 \mathrm{M}$ \\
- BT ION AXIS) & $12 \mathrm{~T}$ \\
- TRITIUM BURNING & $-7 T$ \\
YES
\end{tabular}




\section{FIG. 9, MAGNET STUDY PLAN SUMMARY}

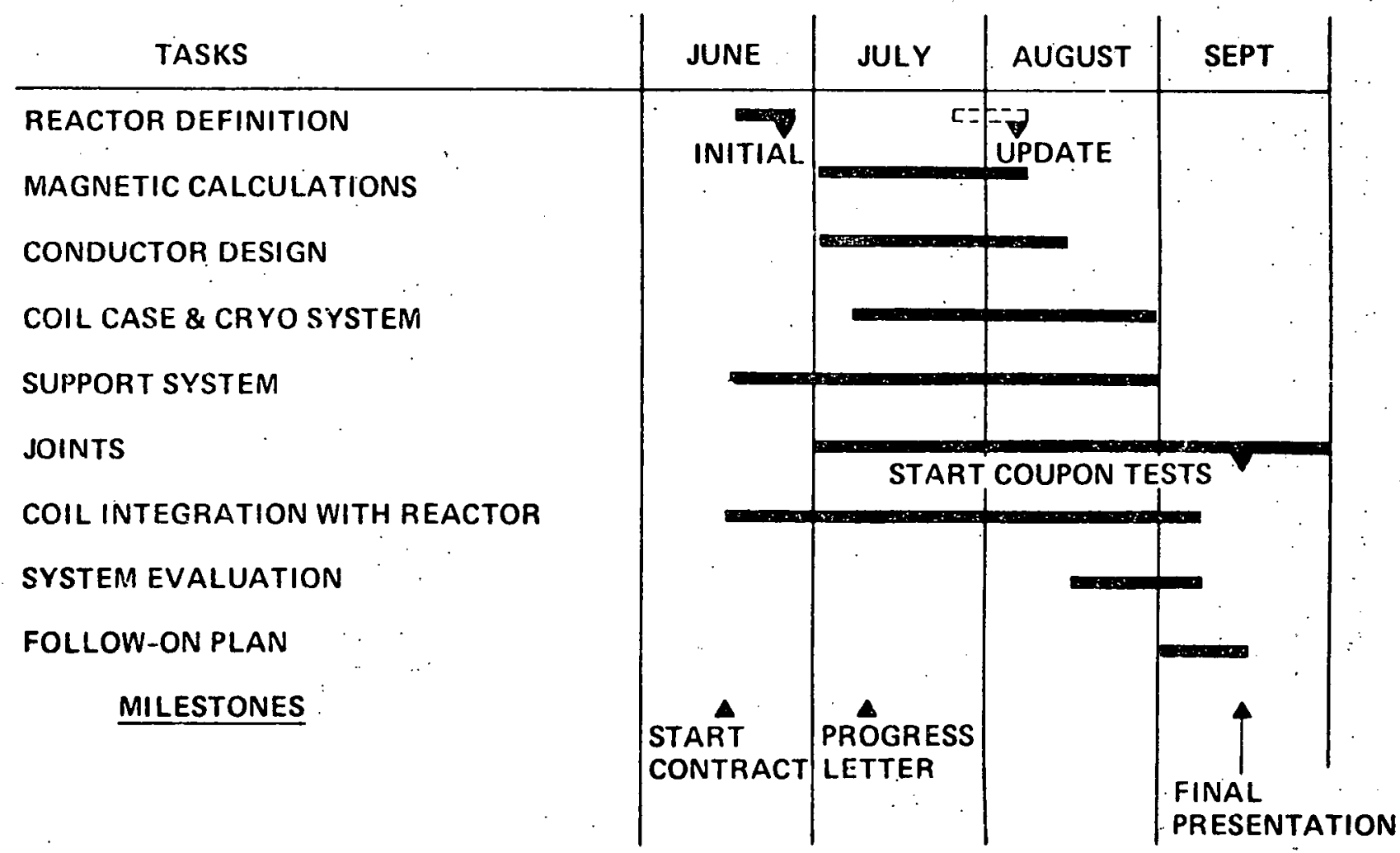


IV. SUPPORT STRUCTURE DESIGN AND ANALYSIS

\section{A. Structural Support and Envelope Requirements}

The DKALS magnet concept was designed around an antictpated post-TFTR reactor. Realistic parameters were chosen by the study group to meet the needs of design for a TFTR upgrade or a TNS device. Envelope requirements for the different components of the reactor were developed. The components and dimensions which evolved are sketched in Figure 10. The ohmic heating and equilibrium field coils can be located either inside or outside of the bore of the toroidal field (TF) coils as needed since the TF magnet system can be taken apart. There was not sufficient time in this study to perform a poloidal field optimization tradeoff. We concentrated our efforts on the arrangements where all ohmic heating coils were located on the outside of the bore of the

\section{FIG. IO, ENVELOPE REQUIREMENTS}

\section{DEVELOPED FOR DEALS POST TFTR UPGRADE}

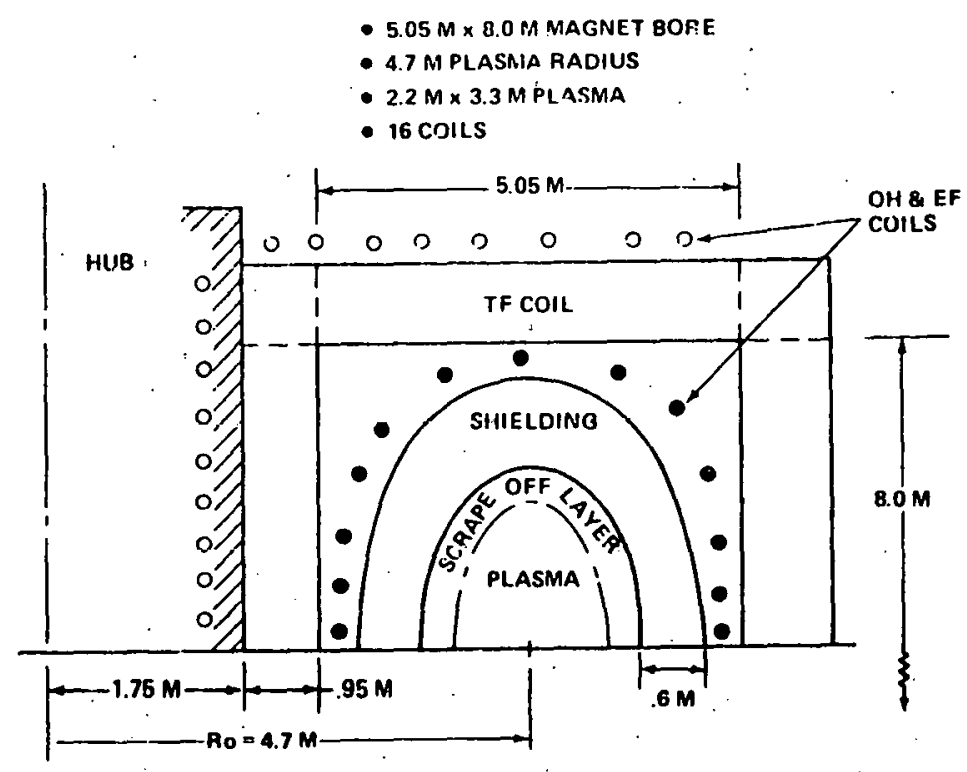


TF coils while the equilibrium field colls were located on the inside of the bore except in the area of the hub. In this region both ohmic heating and equilibrium colls are located between the backing column and the tension post.

The DEALS magnet concept requires a unique support system compared to the more conventional concepts for constant tension TF coil magnet winding. Each leg of the coil must be supported to withstand the electro-magnetically Induced forces which generate the in-plane, out-of-plane and fault loads that act on the coil. In addition, the support structure must be capable of being dismantled in order to permit access to the reactor components and to the DEALS magnet components themselves.

\section{B. Structure Materials}

To minimize the structural weight and simplify the design, manufacturing requirements and cost of the support structure, materials with high yield strength were used. A summary of the support structure materials is given in Table 6. The yield strength of the austentic stainless steels at room temperature was too low to satisfy our needs, and we therefore chose a ferrous alloy (HP-9-4-20) for the room temperature structure. This material was used for the in-plane support structure and the outer torque structure. Discussions were held at Princeton regarding the use of this material at these locations and the effects of its higher magnetic permeability on the magnetic fields. The general consensus was that by maintaining symmetry about the machine midplane the higher permeability of the ferrous steel would have marginal effect on the magnetic fields. Since the ferrous steel surrounds the outside of the TF colls, it will absorb much of the ohmic heating field lines thereby reducing the amount of eddy current heating which would normally occur in the FT colls. 


\section{TABBLE 6, SUPPORT STRUCTURE MATERIAL SUMMARY}

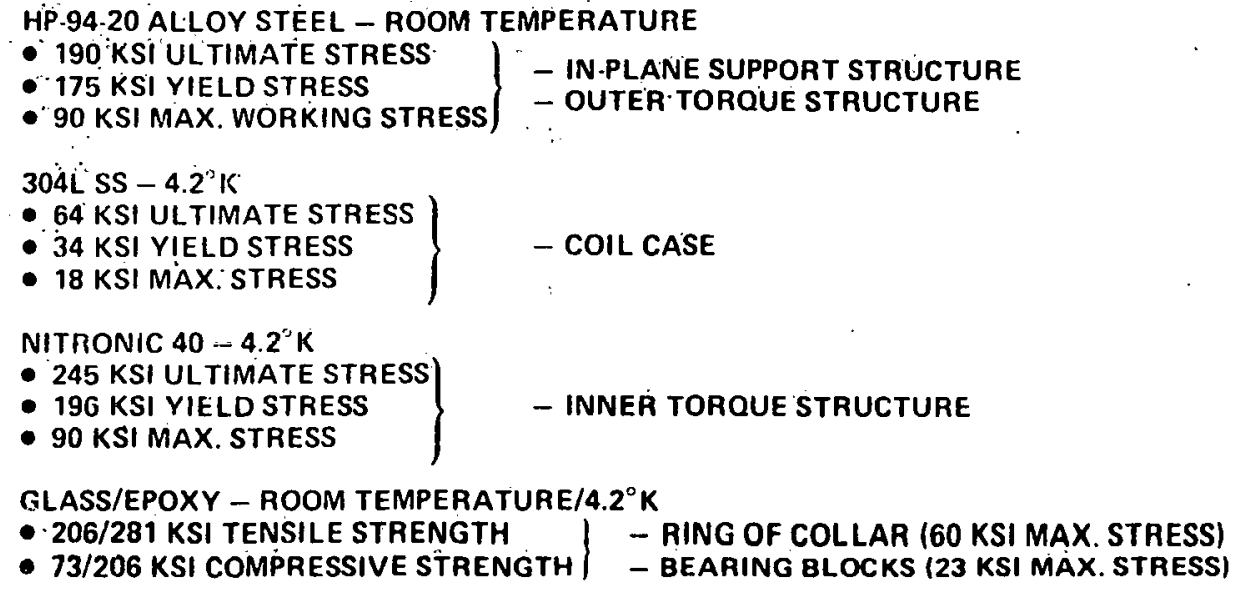

Another advantage of the DEALS concept is that the TF coils operate with a relatively low stress level in the coil and coil case. For this reason the yield strength of 304 stainless steel at $4.2^{\circ} \mathrm{K}$ is adequate in handling the maximum working stress [47 ksi (compressive)] resulting from the various load conditions. The inner torque structure, on the other hand, has a working stress of $90 \mathrm{ksi}$ which requires a material such as the proposed Nitronic 40 with its $196 \mathrm{ksi}$ yield point to provide sufficient margin of safety. For areas requiring electrical discontinuity or thermal isolation as well as strength, the candidate material chosen was an epoxy filled fibre glas. 


\section{FIG. II, IN PLANE STRUCTURAL SUPPORT OPTIONS}
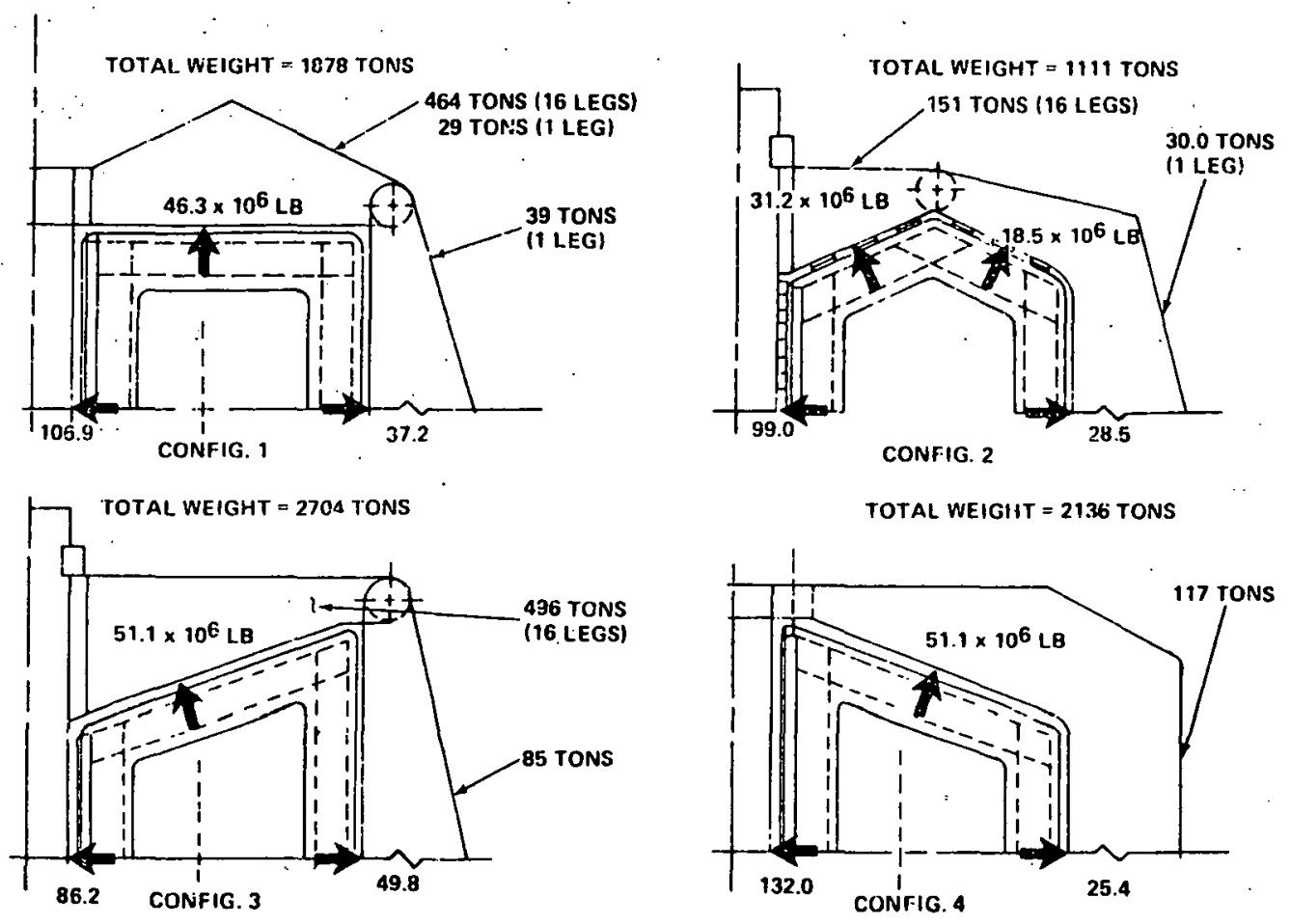

\section{Structural Arrangement Definition}

The first task in defining candidate structural arrangements that could meet the envelope requirements and provide the support of the TF coils was to consider the in-plane loads acting on the TF colls, independently of the out-of-plane loads. Preliminary load calculations were made based on the expected current density of the TF colls and the dimensional parameters established for the machine. The four candidate configurations considered are shown in Figure 11.

The investigation started with the rectangular shape of configuration 1 . In this configuration an Inner TF coll leg produces a force of 107 million pounds acting on a central bucking cylinder and the outer leg pushes against 
an outer support structure with a force of $37 \mathrm{million}$ pounds. In both cases these forces can be handled with little difficulty; however, the problem arises in attempting to support the 46 million pounds generated by the central legs of the coll. These forces may be transmitted to the outer support legs with or without an additional tension tie at the center of the machine. Without the tension tie the welght of upper support structure becomes quite large. With a central tension support the 16 coil upper support structural weight is reduced to 464 tons. This welght presents handling problems in addition to the difficulties associated with physically making a tension joint connection. An alternative solution is to reduce the amount of load seen by the central tension column and increase the load acting on the more accessible outer support leg. Configuration 2 illustrates such an approach. Here, the outer support leg is brought around to some point toward the center of the machine where a multiple finger joint is made. A.trade-off must be made in the location of this joint, between accessibility in making the joint connection on the one hand and reducing the load transmitted to the central support column on the other. We assumed the joint to be located along the vertical center line of the bore of the TD coils in this study. This configuration offered the most promise in supporting the TF coils, together with improved - handling of and accessibility to the component parts; it was therefore chosen as the baseline for further investigation. "The other two configurations (2 and 3) were adaptations of the first. However, they were discounted, efther because they were too heavy, there was inadequate access to make the central joint connection, or both these disadvantages existed. 


\section{FIG. I2, IN PLANE /OUT OF PLANE FORCES}

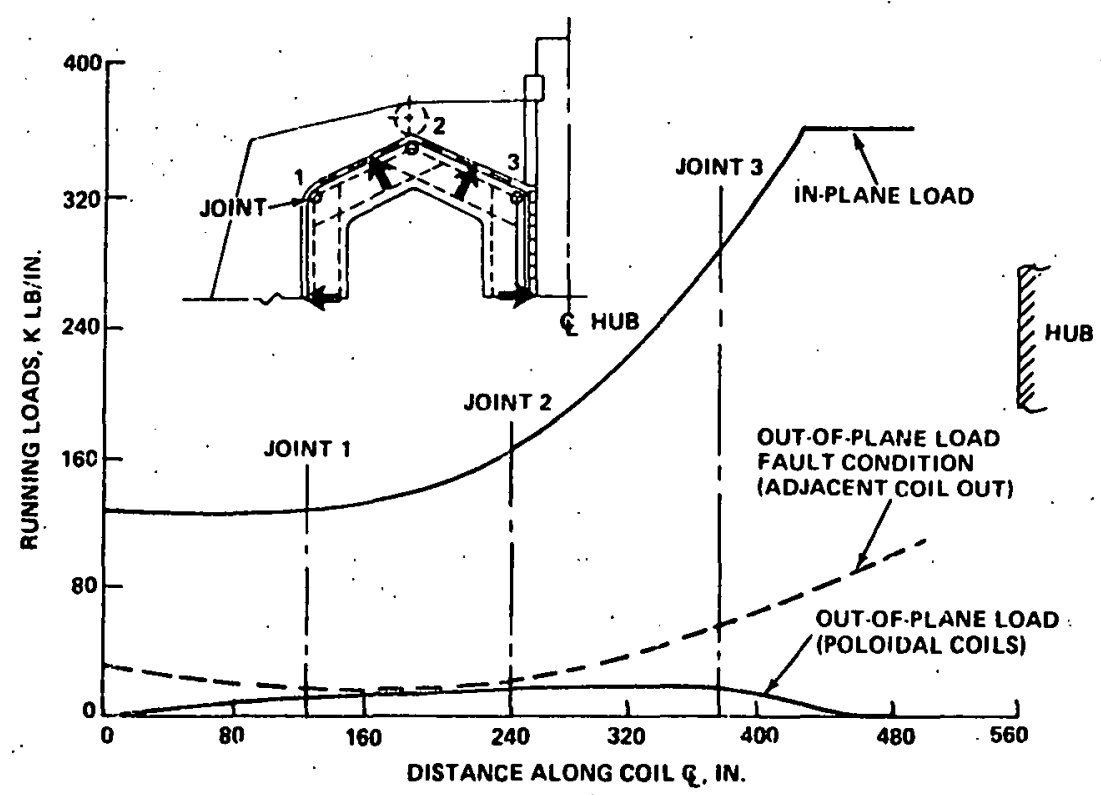

D. In-Plane/Out-of-Plane Forces

Figure 12 shows the resulting in-plane, out-of-plane and fault condition loading for the coll arrangement shown in configuration 2 of Figure 3 . The in-plane load increases from 130,000 1bs/in. along the outer vertical magnet leg to $360,000 \mathrm{lbs} / \mathrm{in}$. acting on the inboard vert1cal leg. Out-of-plane loading resulting from the pololdal fields is significantly lower than the In-plane forces. The out-of-plane load is shown to peak midway between the first and second foint; it remains somewhat unfform through the third joint and decreases thereafter. The fault load produces the greatest out-of-plane loading conditions. However, with sensing devices to discharge all the TF colls uniformly in case of a coll fallure, the extent of these forces could be greatly reduced and posstbly eliminated. 


\section{FIG. 13; BASELINE CONFIGURATION- DEALS TYPE POST-TFTR UPGRADE}

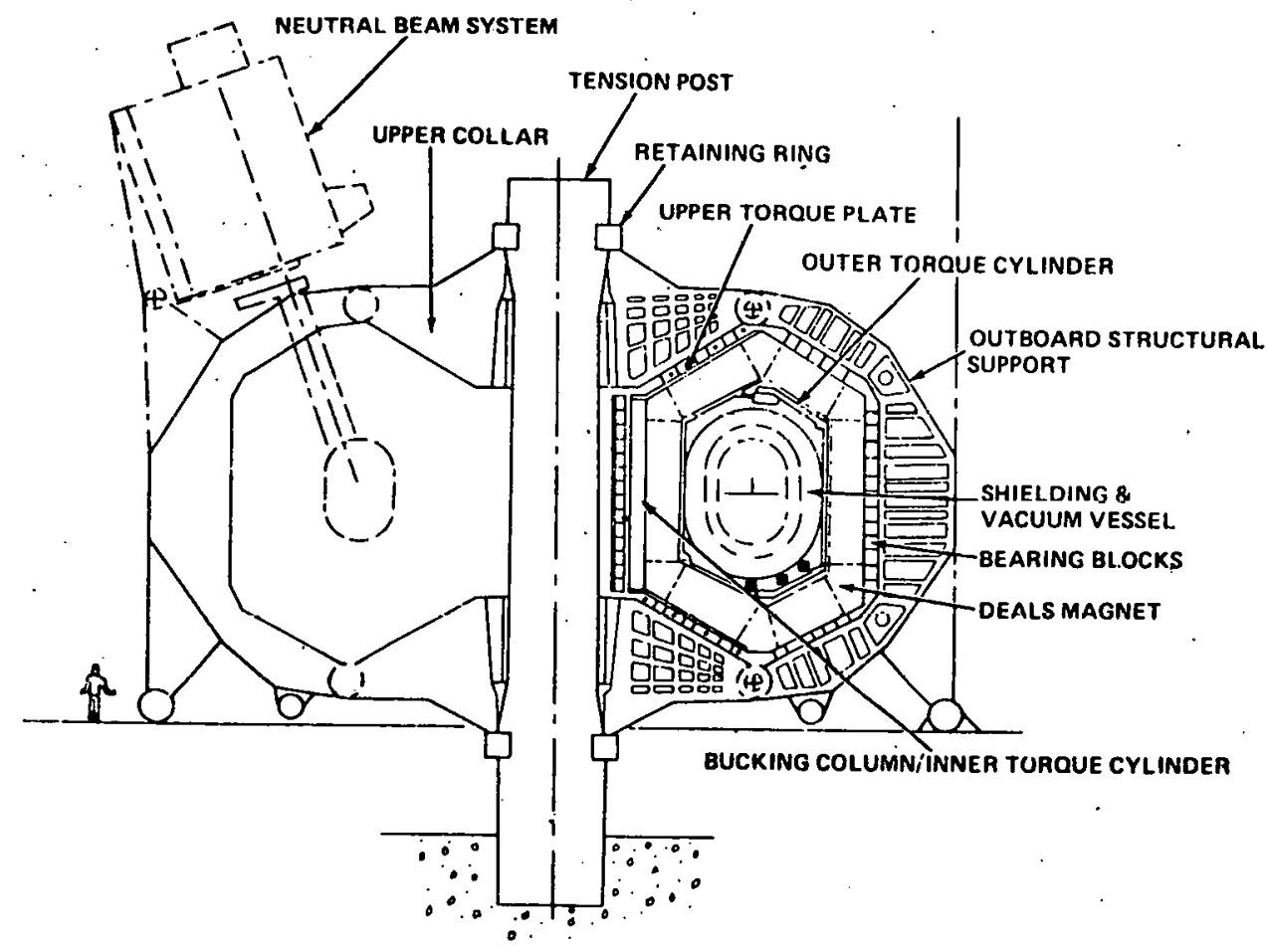

\section{E. Baseline Configuration}

The baseline structural arrangement of the DEALS magnet concept can be seen in Figure 13. The TF colls are made up from six straight segments with finger joints located at each end to form an elongated hexagonal shape. The joints are designed to allow the segments to contract independently of each other during the cool down period (room temperature to $4.2^{\circ} \mathrm{K}$ ) and to move slightly with respect to each other when the magnet winding is energized. : Once cooled to the operating temperature the TF coils are slowly energized, generating outward forces which are reacted on the support structure.

The outboard magnet legs transit thelr load through epoxy filled fibreglas bearing blocks to the outboard structural support. Although the major fraction of this load is transmitted directly to the foundation, reaction loads are 


\section{FIG. I4, BASELINE CONFIGURATION - TOP VIEW}

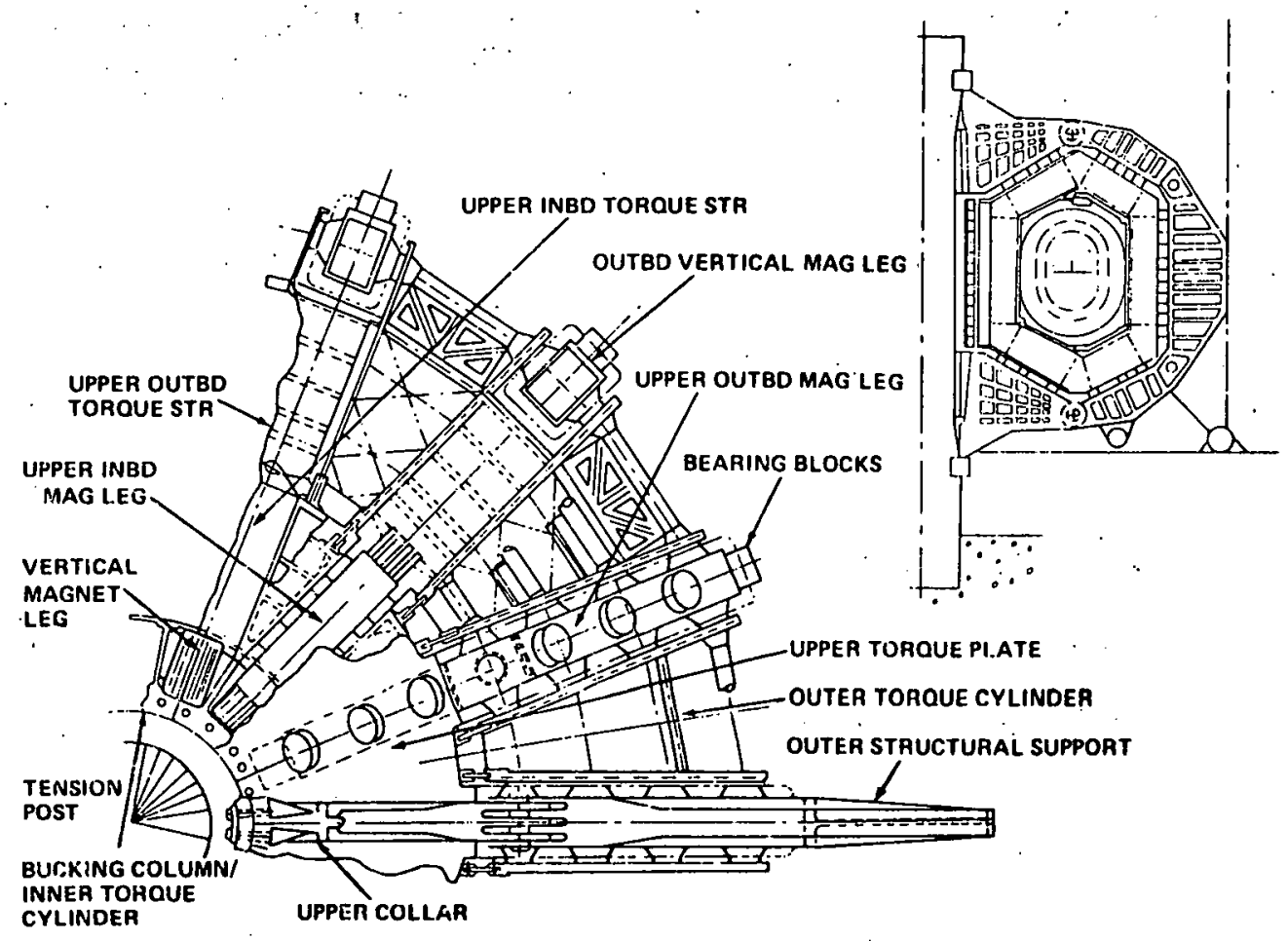

produced at the upper and lower collar pin connection joints. The vertical component of this reaction, as well as the vertical load on the upper collar, is reacted at the tension post through the retaining ring. The horizontal loads acting on the upper collar are transferred to a continuous epoxy filled, fibreglas ring as a tension and compression loading. A similar reaction occurs at the lower collar. The inner vertical magnet leg transmits its load to a bucking column which serves as an integral bucking column and torque ring cylinder. The outboard structural support, the upper and lower collar supports and the tension post structure serve only to support the in-plane forces. The out-of-plane, tippling forces are supported by an independent inner and outer torque cylinder.

The top view of the machine is shown in Figure 14 with the structure pealed back to reveal the different components. The inner torque structure consists 
of concentric cylinders which are interconnected by intermediate supports wedged between adjacent vertical magnet legs. The inner ring also serves as the compression buckling column. The outer torque ring is made up of shear webs and truss structure and is located between the outer vertical legs and the plasma shielding. The webbed area of the outer torque cylinder makes up part of a channelled structure extending over the entire TF coil, except for the inboard vertical $1 \mathrm{eg}$, supporting the weight of the unenergized magnet legs. The channel is backed up at discrete intervals with a truss tube and web arrangement which transmits out-of-plane loads down to the torque structure and also serves as the support system for a fault conduction in the event that a TF coil fails.

F. Finite Element Model

A two and three dimensional finite element model of the TF coil support structure was generated (see Figures 15 and 16). A number of in-plane models of different structural arrangements were conceived before the one shown was studied in depth. Although this model has not yet been fully optimized, it does appear to offer an effective arrangement for supporting the TF coils and, compared to other configurations investigated, it is the lightest weight structure.

The coll in-plane loads are transmitted through a finite number of bearing blocks to the support structure. The load is shown varying from 4.7 million to 13.3 million pounds. The resulting stress buildup in the $T F$ coil and coil case at various locations is shown in Figure 17 with the maximum stress developed being a compressive stress of 47,200 at the foint bridge at the Inboard end of the upper inclined inside coll segment. The support 
FIG.15, FINITE ELEMENT - IN PLANE LOADING $\left(10^{6} \mathrm{lb}\right)$

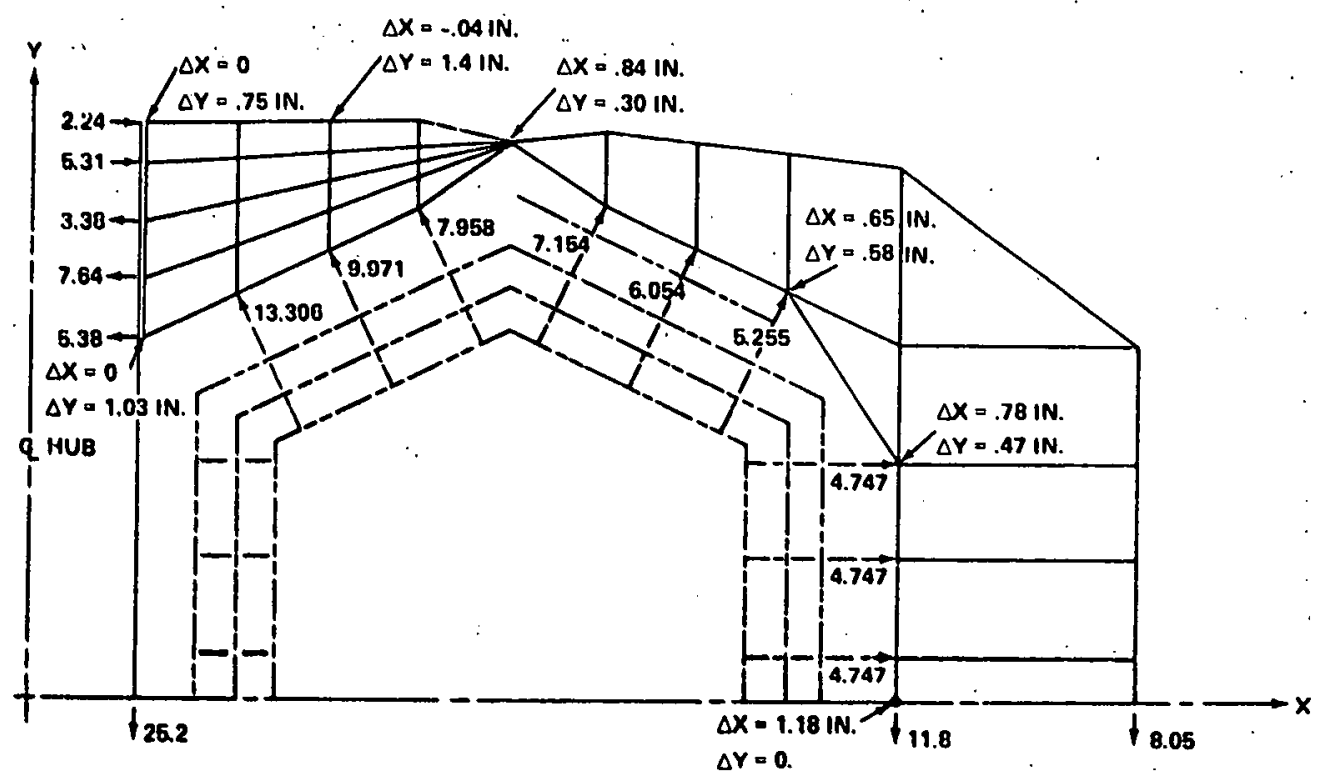

FIG. 16, FINITE ELEMENT MODEL - OUT OF PLANE LOADING $\left(10^{6} / \mathrm{b}\right)$

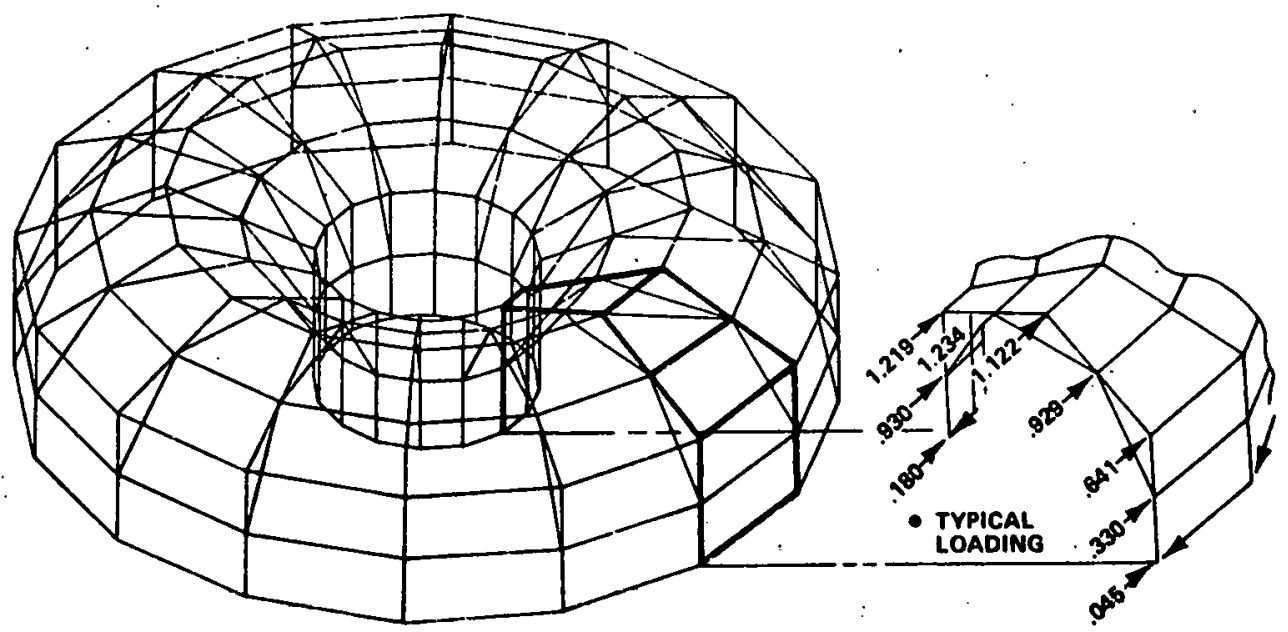




\section{FIG. 17, COIL STRESS SUMMARY}
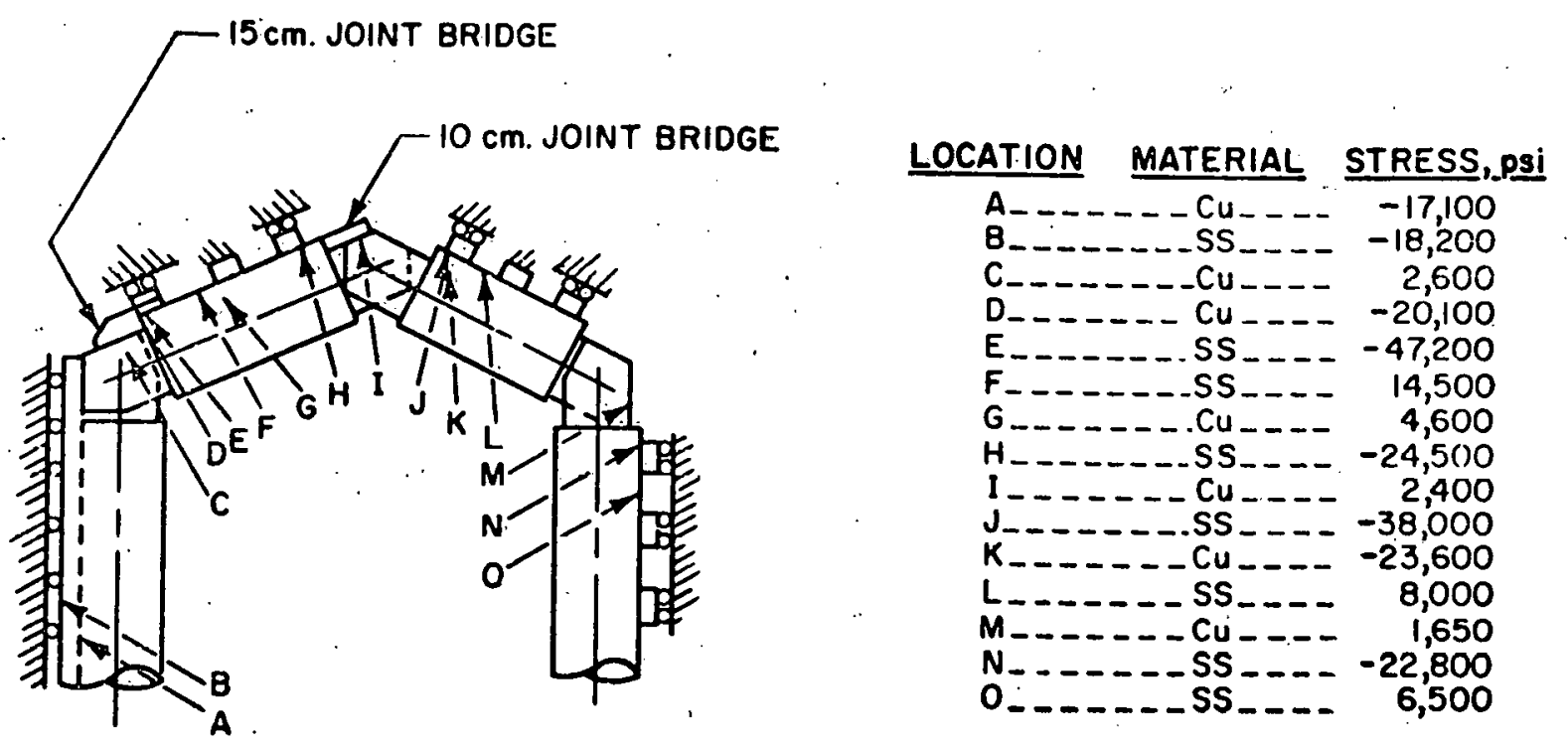

structure is fully stressed. This was achieved by allowing the structural area to be reduced incrementally until the material is stressed to its allowable material stress. The deflections at various points in the model $(\Delta x, \Delta y)$ are highiighted along with the reaction loads for this fully stressed design. The structural arrangement and area distribution of the collar was developed after a number of design iterations. These were aimed at producing a more uniform distribution of the load across the continuous epoxy filled fibreglas insulating ring which constitutes the collar. The resulting load distribution along the collar, shown in Figure 15, was acceptable from the point of view of being able to make such a ring and the posstbility of it supporting such a load.

The three dimensional model (Figure 16) was used to determine the relative out-of-plane motion across the foints. Under the operating load distribution 
FIG. 18, MANUFACTURING PROCEDURE FOR TY.PICAL STRUCTURAL MEMBER
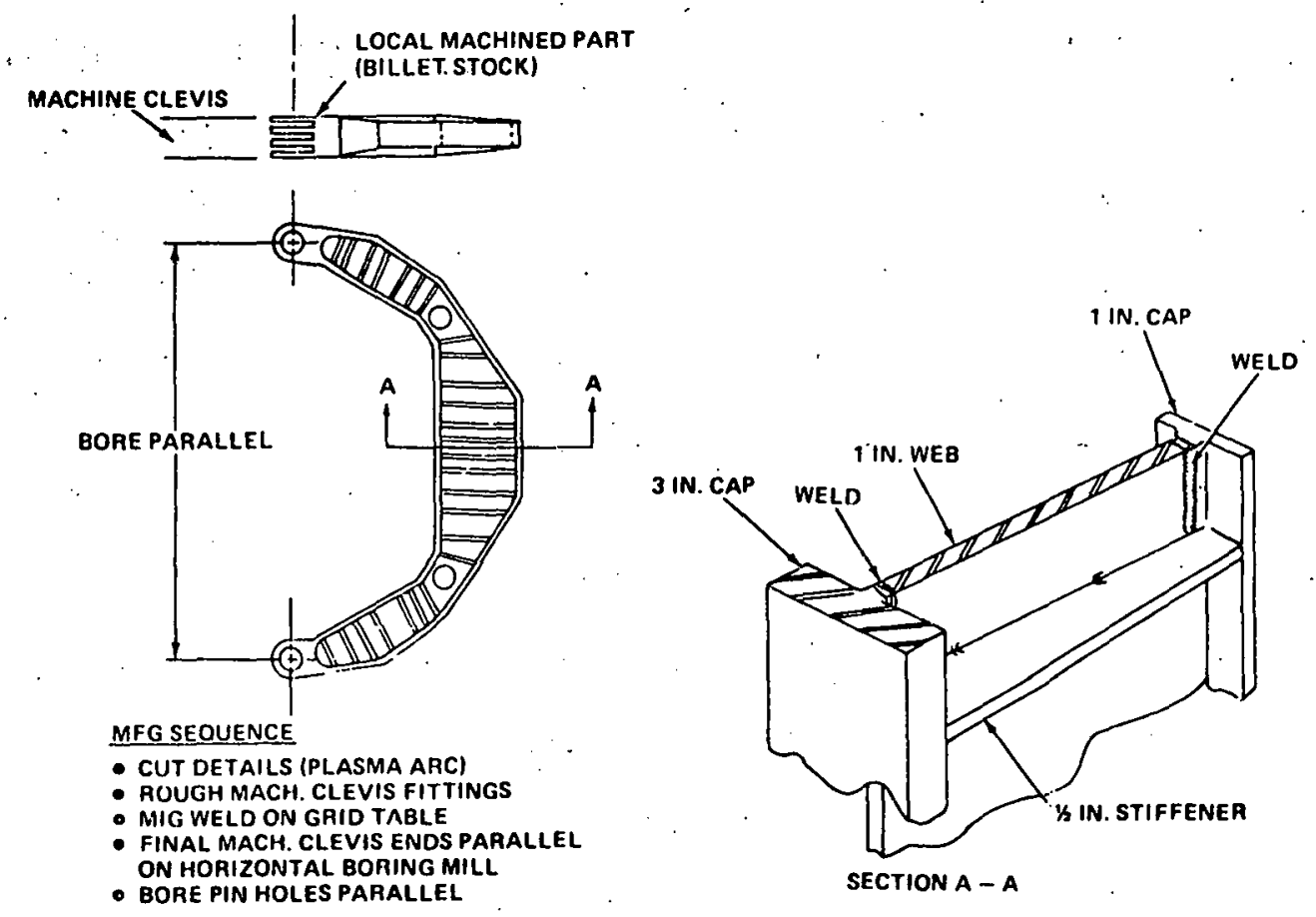

shown (given in millions of pounds) a maximum out-of-plane deflection of 0.34 Inches occurred across the top of the structure for a fully stressed model. Much more effort is required to define the out-of-plane structural model and its relationship to an independent in-plane structure so as to accurately determine the stresses and motion of the component parts. Our objective during this preliminary study phase was to determine the extent of motion, (would it be 10 inches or 1 inch?) and to assess whether or not the structure we envisioned was capable of supporting the expected out-of-plane loads. The results indicate that the deflection is small and that it is posstble to concelve and design a suitable independent out-of-plane support structure.

\section{G. Manufacturing Procedure}

The manufacturing procedure for the outboard structural support is shown 
In Figure 18, typifying the make-up of the in-plane structural members. This structure would be made up of welded stiffened web and cup plates with the thicker cup located on the bore side. A multi-fingered joint would be rough machined out of a billet and welded in place with final machining of clevis ends and pin holes parallet on a horizontal boring mill.

\section{H. Coil1 Case Design}

The coil case performs three functions. First, it is the initial support member for the magnetic loads. It also acts as the liquid helium dewar for most of the magnet and contains machined grooves which act as flow return channels for the coolant. The adequacy of the case to meet the support requirement was determined through detailed structural analyses. The capacity of the case to fulfill the last two requirements are simply a matter of design.

The coil case (Figure 19) has a simple rectangular section made from $304 \mathrm{~L}$ stainless steel. It is $5 \mathrm{~cm}$ thick on three surfaces and either $5 \mathrm{~cm}$ or $10 \mathrm{~cm}$ thick on the load bearing surfaces $(5 \mathrm{~cm}$ for the vertical legs and $10 \mathrm{~cm}$ for the inclined legs). The inner and outermost surfaces have an additional $1 \mathrm{~cm}$ of thickness which is machined to create rectangular coolant flow channels. These channels, $0.6 \mathrm{~cm}$ wide $\times 1 \mathrm{~cm}$ deep are machined at an angle as in Figure 19, to permit the passage of coolant while still serving as a support surface against which the plate type conductors react. The coil case is shorter than the conductor plates, see Figure 19, so as to allow complete access to the joints between adjacent segments of each turn. In the joint regfons, maintenance of the helium dewar is achieved by the use of the joint collar-bellows assemblies which are welded to the coil case on final magnet assembly. 


\section{FIG. 19, COIL CASE DESIGN}

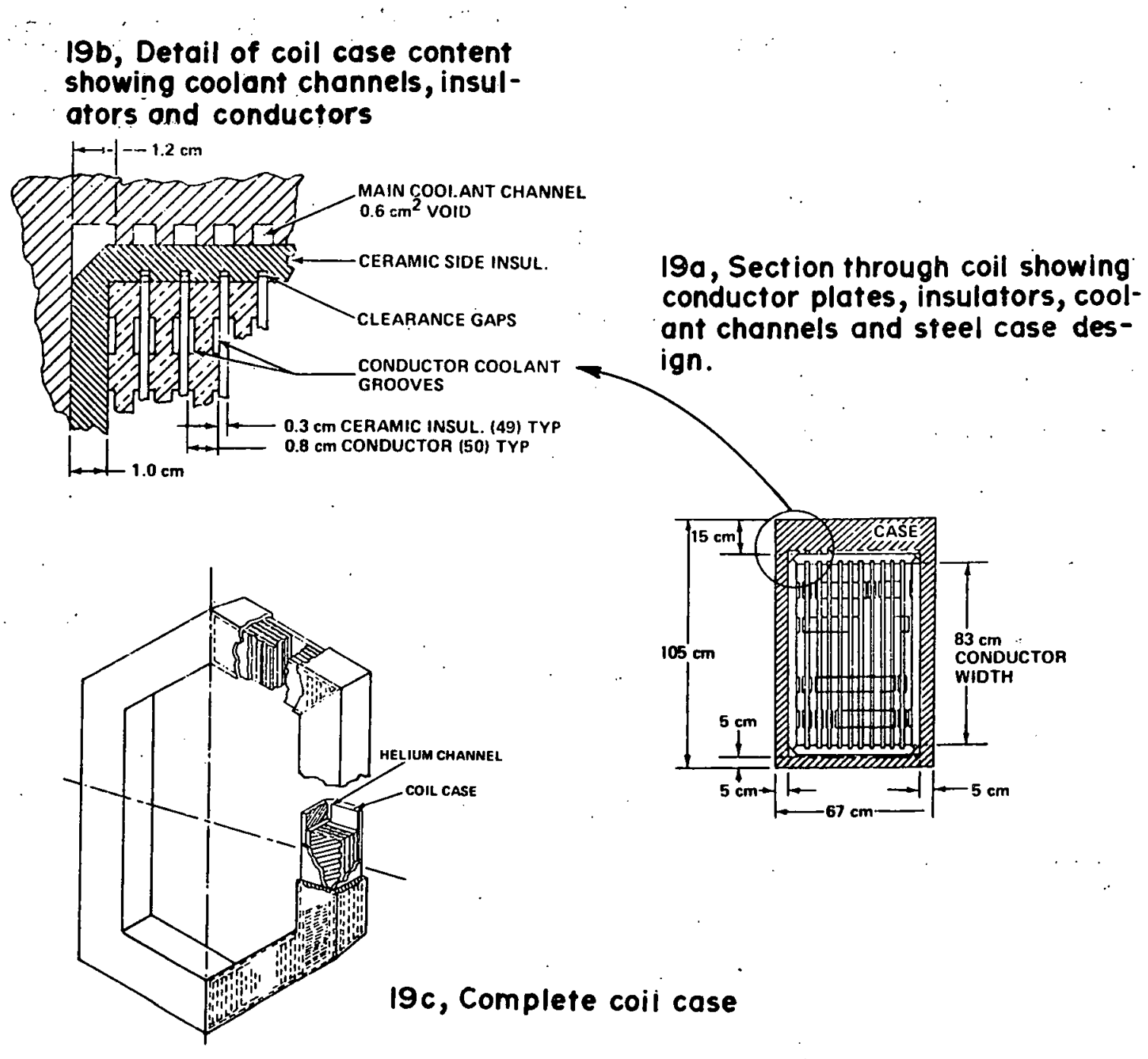

No difficulty is foreseen in the manufacture of the cases as the material of construction is a readily machined and welded grade of stainless steel. The case will be formed of precision rolled plate elements. Following machining, the plates will be welded to each other. This could be followed by a broaching operation and the case would finally be shrunk to fit over the conductor-ceramic bundle. Alternatively, the case side walls and the conductorceramic bundle could first be stacked, a pressure could then be exerted on the stack, and the inner and outer sides then welded using electron beam welding 
techniques. The weld should not pose a problem as the weld Ine will foilow the coolant flow channels which extend longitudinally in each corner of the case.

The structural adequacy of each case was assessed by using finite element analysis techniques. The finite element grid used to model a single case consisted of 1064 triangular elements and 585 nodes. The material properties of each region were correctly modeled, although the composite conductor plates were treated as homogeneous copper plates for stress purposes. since the amount of superconductor is small compared with the overall section. Loads were assumed to act normal to the conductor longitudinal center line and were distributed as a linearly varying body load on the copper, maximum on the inner surface, and null on the outer surface. Each case was assumed to act independently and was taken fixed at the three support pads, or for the case of the innermost leg, along the bucking cylinder surface. In the joint regions, the copper was assumed to be unsupported for the outer legs while supported by the cases at the inner joints. At the Innermost joint, a bridging member of stainless steel was employed to increase the effective case thickness to $15 \mathrm{~cm}$ over the joint.

A summary of the pertinent stress results is given in Figure 17. The stress field is seen to be predominantly compressive. The maximum stress is a bearing. stress of 47,200 psi compression occurring in the stainless steel bridging member of the inboard case at the inboard support pad. This stress is in excess of yield but below the ultimate level and can be expected to relleve under local yielding. The maximum stress in a conductor element 
1s 24,500 psi compression occurring at the case-conductor interface on the Inboard leg. Again, this is a local bearing stress which can be expected to relleve after local yielding. The maximum tensile stress in a conductor element 1s 4,600 psi tension occurring at the case-conductor interface on the inboard leg, adjacent to the center support. Since the $\mathrm{Nb}_{3} \mathrm{Sn}$ superconductor should be capable of withstanding a tensile strain level of $0.1 \%$ before fallure. (equivalent to 17,000 psi stress level in copper) this stress has a safety factor in excess of three.

Overall the case-conductor stress levels are considered to be satisfactory. The local stress concentrations which occur are due to the discrete nature of the support pads and the lack of support over the joint regions. Lower and more unfform stress distributions could be achieved with a shift. to closely spaced, smaller support pads and additional support pads over the joints. 


\section{REACTOR ASSEMBLY AND ACCESS}

\section{A. Reactor Accessibility}

One of the key feasibility issues addressed in this study was that of reactor accessibility. The design of the structural support system must permit toroidal field magnet demountability and the ability to remove and replace all reactor components.

In addition it should be possible, if necessary, to carry out all assembling or dismantling operations remotely because of the induced radioactivity in the reactor components resulting from long term reactor operation. This is true for an ignition or power reactor; it would not be required for an experimental hydrogen device where the radioactivity problem does not exist.] The following section outlines a typical reactor assembly sequence in which the major reactor components can be assembled and integrated.

\section{B. Malntainability and Access}

As indicated in the previous description of the baseline configuration and the reactor assembly sequence outlined in the following pages, the passive support structure does not impair accessibility to the reactor. All reactor components are accessible by reversing the proper combinations of assembly procedures and can be removed. Toroidal fleld magnets can be demounted, and falled magnet segments replaced. Each of the three outboard magnet legs is accessible by removing the upper and lower support structure pins and rolling back the outboard structural support assembly. The inboard magnet legs are accessible by removing either the upper, or lower retaining ring and collar assembly.

Thus we believe that this DEALS magnet concept results in easier assembly and maintainability of the toroidal field magnets and other reactor components, which should reduce life cycle costs. 


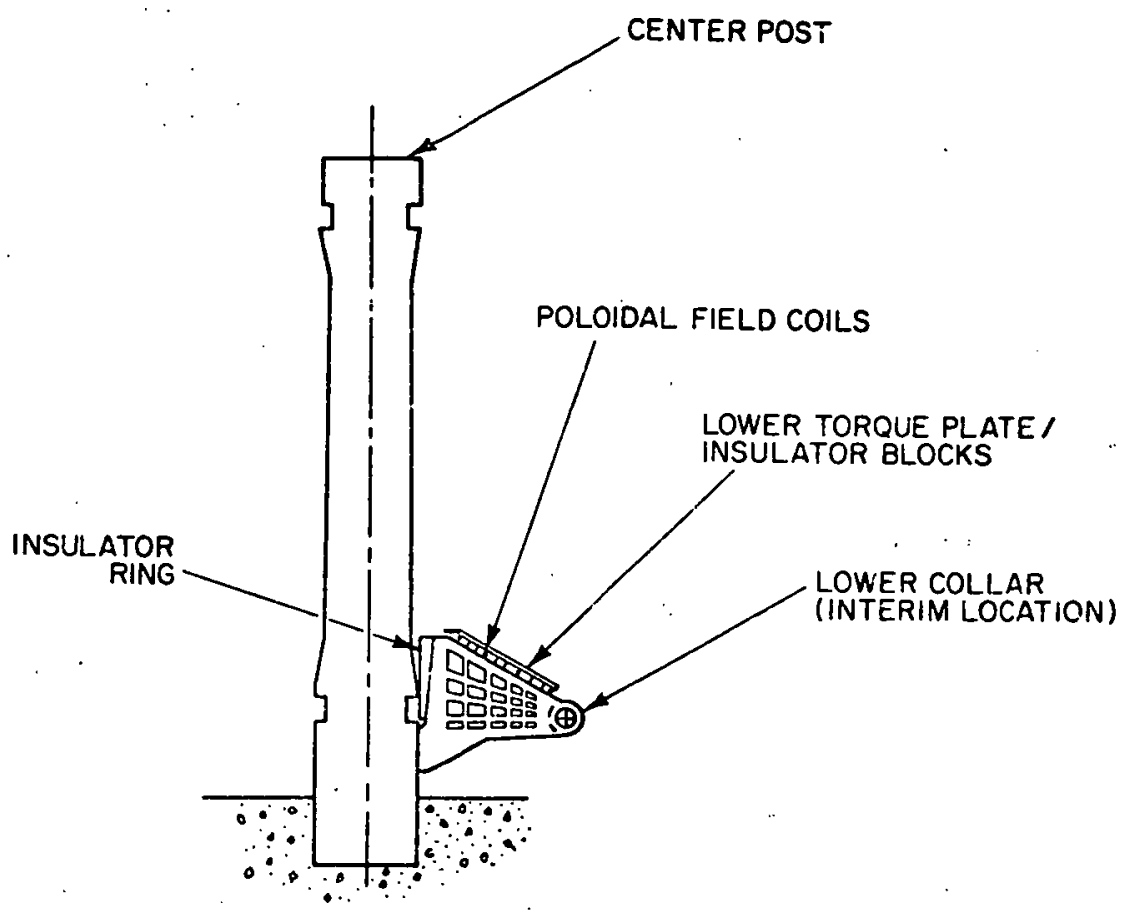

FIG. 20, ASSEMBLY SEQUENCE I

The center tension post is first lowered into place and embedded in the concrete foundation. It consists of 16 wedge shaped pieces strapped together to form the tension post with electrical insulating material between adjacent sections to reduce eddy currents. The tension post can be lowered into place as one section or each of its 16 components lowered into place separately, if It is necessary to reduce the maximum load on the overhead crane. The lower collar and the insulator ring are then lowered into a temporary location in the basement and the lower poloidal field colls and lower torque plate/ insulator blocks are seated above the lower collar. This entire assembly is later repositioned during the third step in the assembly sequence. 


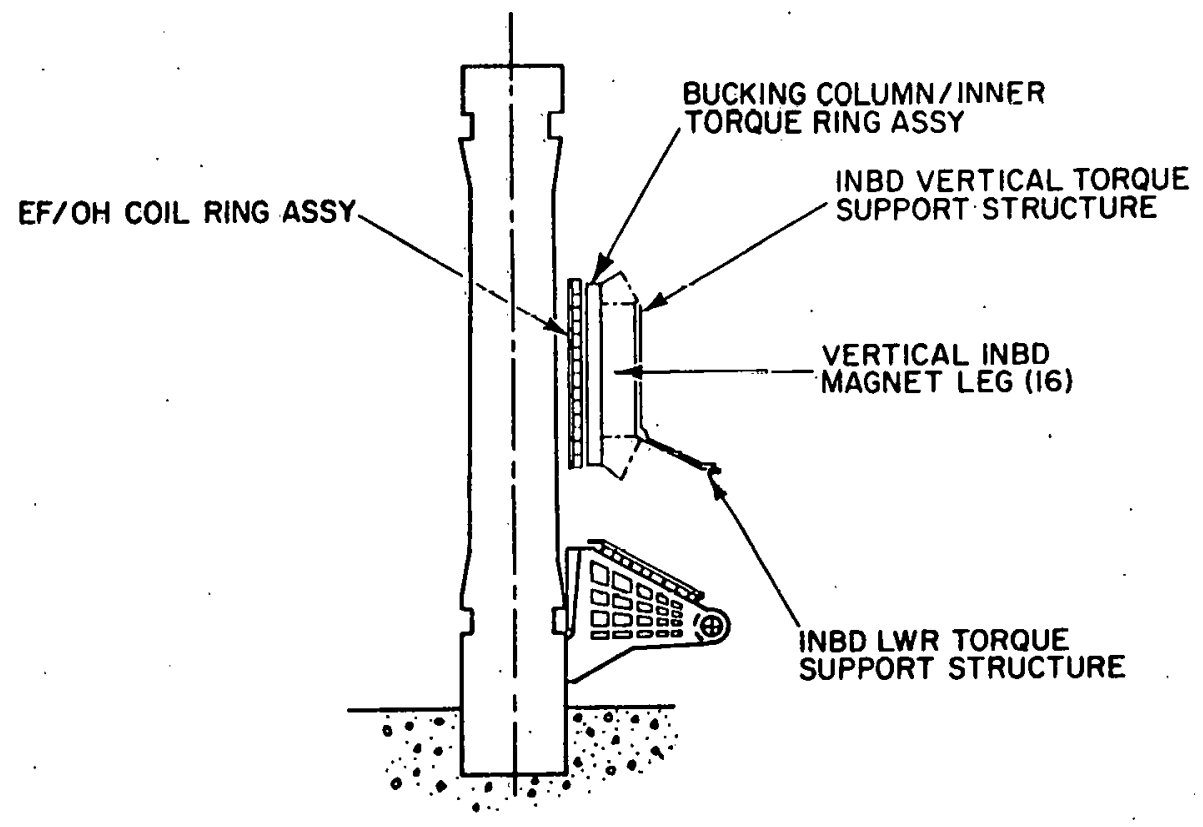

FIG. 2I, ASSEMBLY SEQUENCE 2

The bucking column and inner torque ring assembly next is lowered into its final position. The equilibrium field and ohmic heating coil ring assembly is then placed between the bucking column and the tension post.

The Inboard vertical, and lower torque support structures are assembled and each of the 16 vertical inboard magnet legs is then Inserted into its channel and locked into place as shown above. 


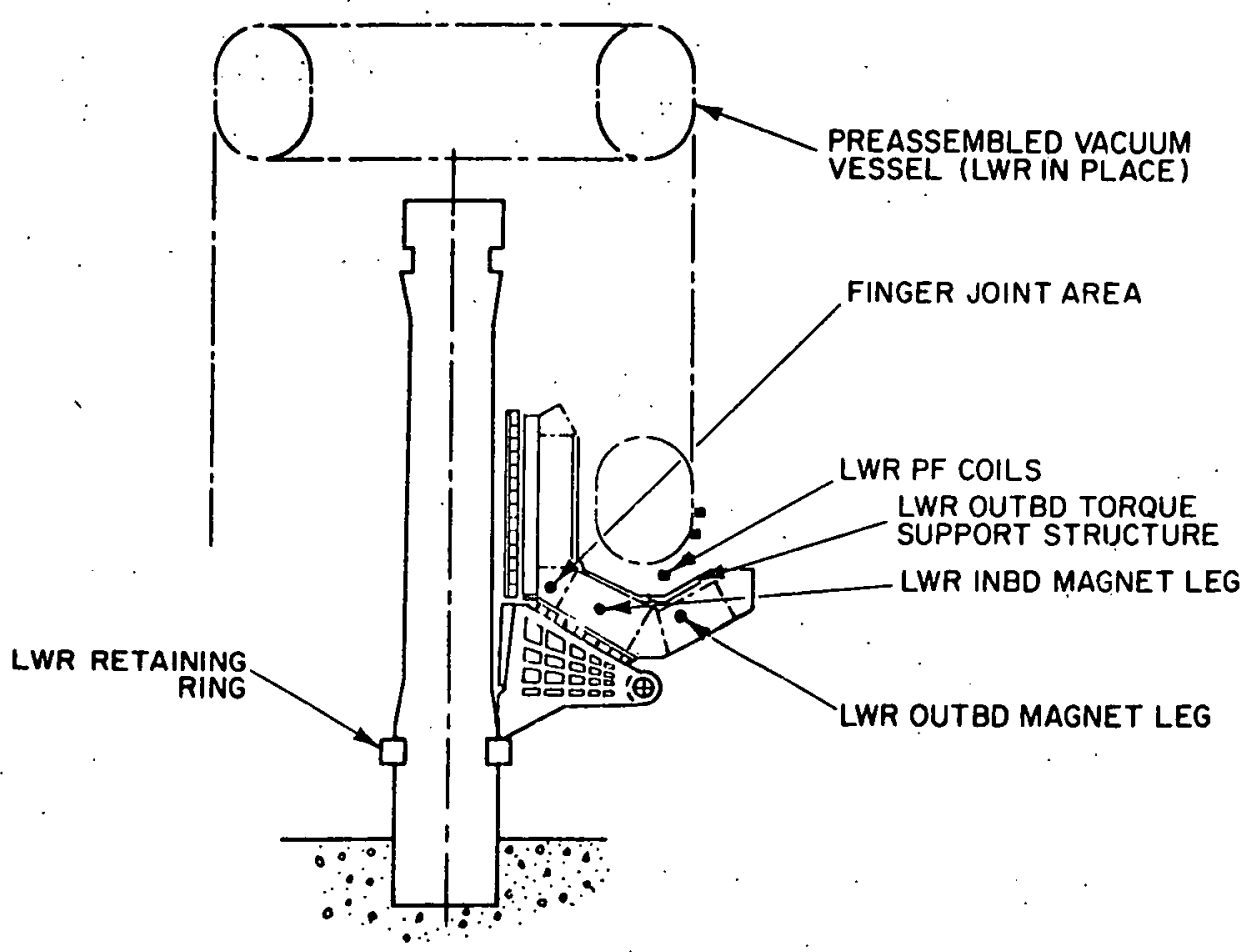

FIG. 22, ASSEMBLY SEQUENCE 3

Each of the 16 lower inboard magnet legs is installed in place and the mating finger joints of the magnet segments are connected. The helium and vacuum deware are then connected. At this point the lower outboard poloidal fleld colls are installed followed by the lower outboard torque support. structure. Each of the 16 lower outboard magnet legs is then positioned and the mating finger joints connected. The lower collar assembly is now raised (from its temporary position) to its final position and locked into place by the lower retaining ring followed by the vacuum vessel, which can be preassembled and tested off-line if desired. 


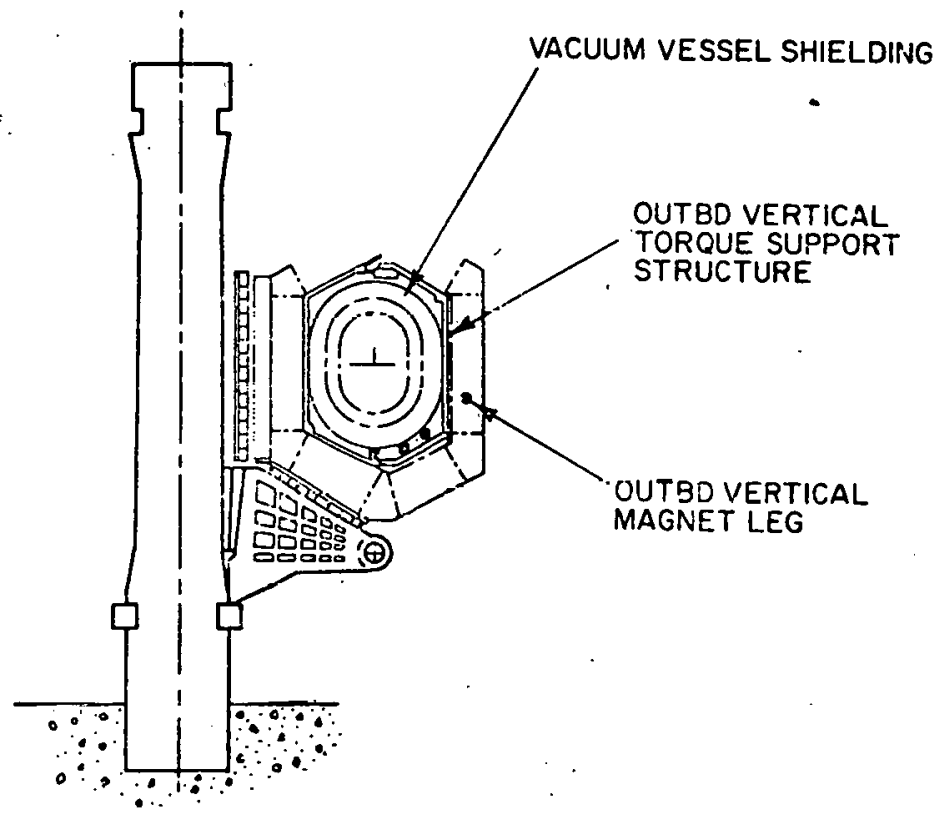

FIG. 23, ASSEMBLY SEQUENCE 4

At this stage the vacuum vessel shielding is installed and the outboard vertical torque support structure is erected. Each of the 16 outboard vertical magnet legs can now be placed in prisition and the mating finger joints connected. 


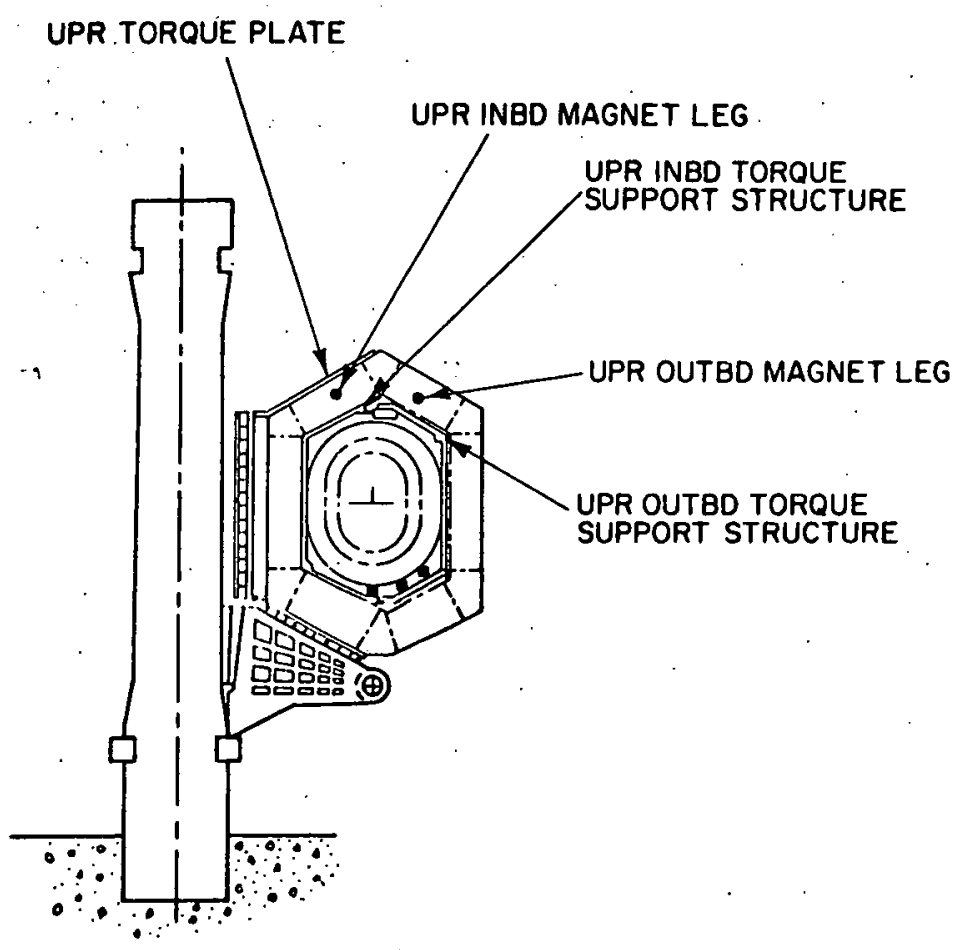

FIG. 24, ASSEMBLY SEQUENCE 5

The fifth stage in the assembly procedure involves the installation of the upper outboard and upper inboard torque support structure. Each of the 16 upper outboard magnet legs are put in place and the mating finger joints are connected. This sequence is followed by lowering each of the 16 upper inboard magnet legs into place. Since these are the last of the magnet legs to be installed, mating finger joint connections are required at both ends of the magnet leg. The last step in sequence 5 is then to place the upper torque plate and insulator blocks in the assembly. 


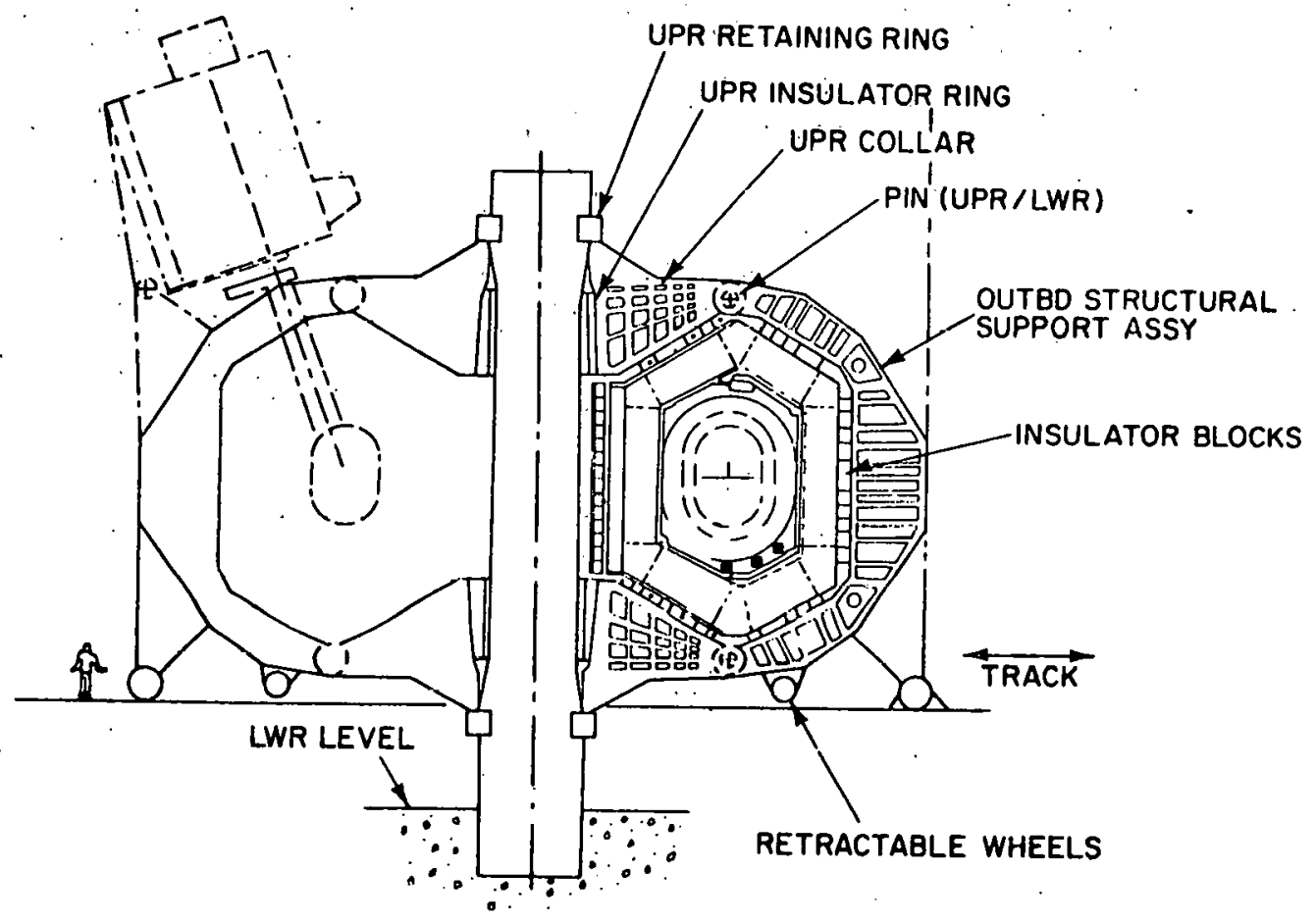

FIG.25, ASSEMBLY SEQUENCE 6

The upper poloidal field coils, upper insulator ring and upper collar are now lowered into position. The upper collar assembly is then locked into place by the upper retaining ring. (This sequence mirrors the lower collar assembly in sequence 3. )

The outboard insulator blocks are installed at this point and each of the 16 outboard structural support assemblies is wheeled into place along tracks. After each of these assemblies 1s properly aligned, the assembly sequence is finally completed by inserting the upper and lower pins as shown above.

The entire sequence is shown at a glance in Figure 26, as a further aid to understanding the concept. 

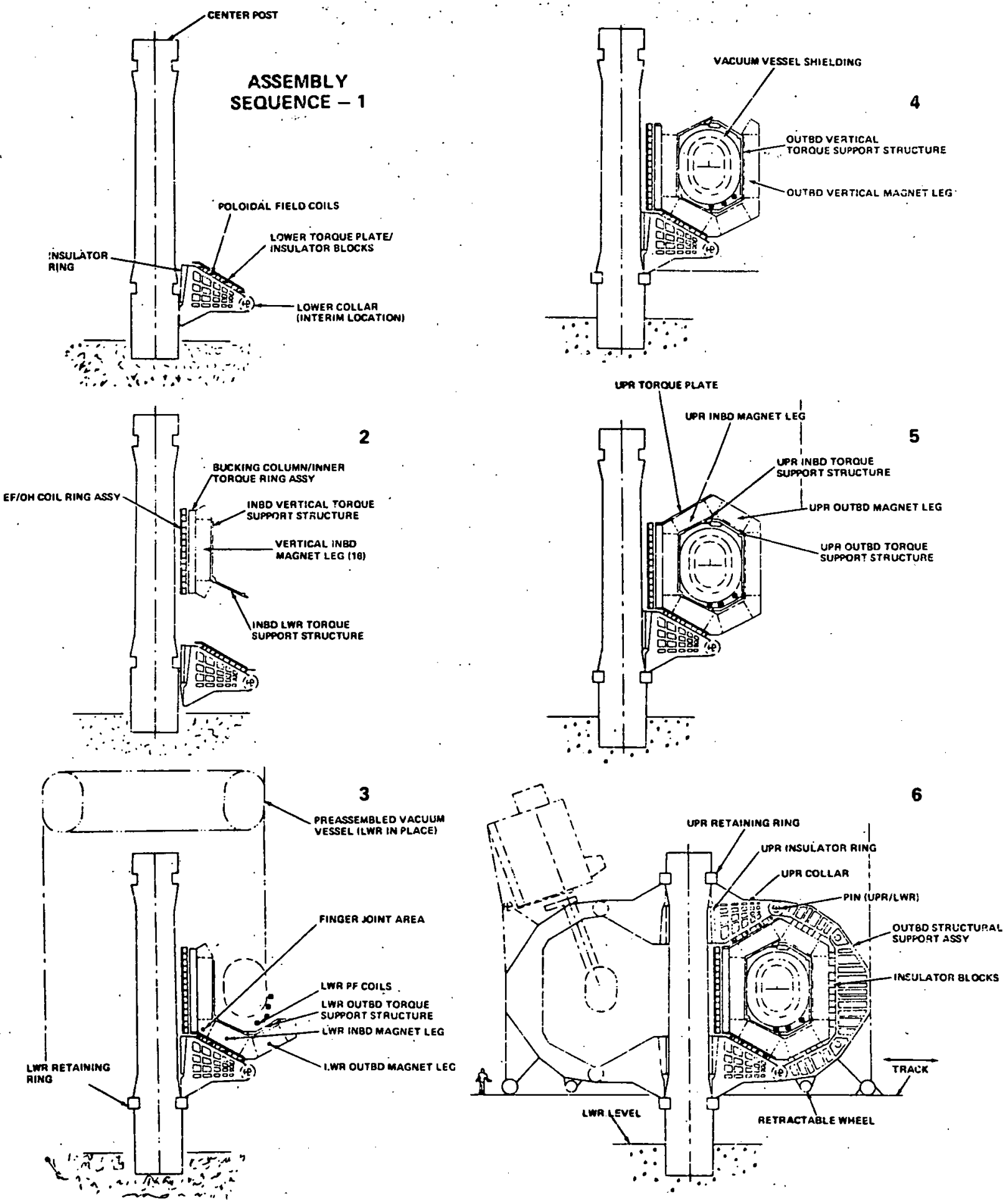

FIG. 26, TOTAL ASSEMBLY SEQUENCE I TO 6

Assembly Sequence for DEALS System: This shows how the system could be assembled or dismantled, starting with the outer tension post (Step 1) and moving through installation of inboard magnet legs and torque structure (2), vacuum chambers (3), the rest of the magnet ( 4 and 5); and finally the outboard gtructural support (6). 


\section{FIG. 27, DEALS HFITR CONDUCTOR CONCEPT}

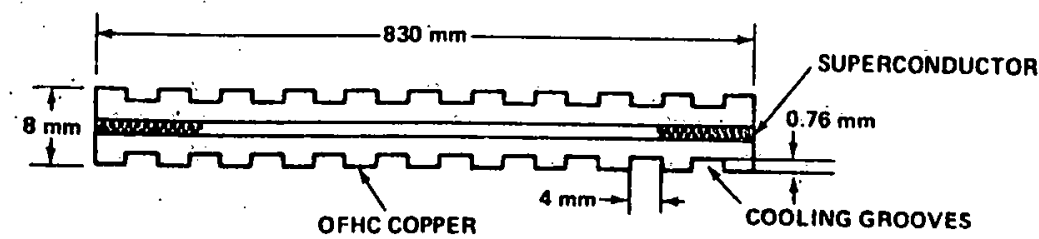

- CROSS-SECTION THRU CONDUCTOR

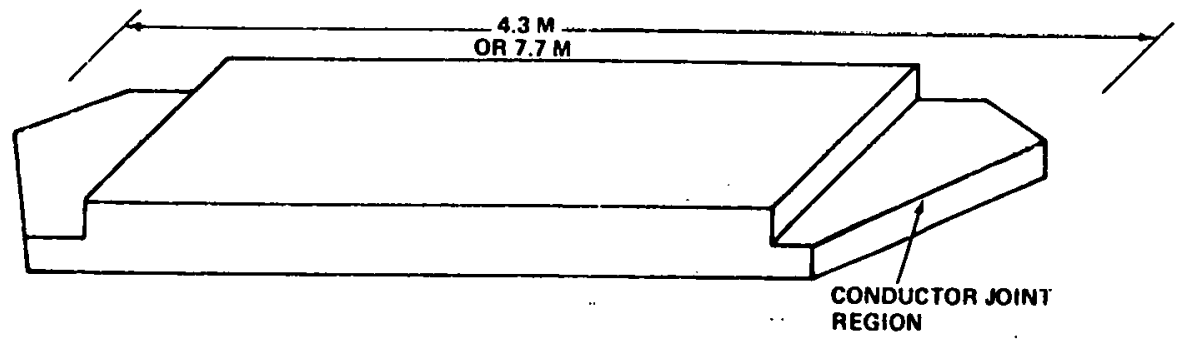

- FINISHED CONDUCTOR PLATE (COOLING GROOVES NOT SHOWN]

VI. TOROIDAL FIELD COIL ANALYSIS AND DESIGN

A. Conductor Design and Cooling

The cryostable conductor consists of fully transposed $\mathrm{Nb}_{2} \mathrm{Sn}$ copper braids [83 $\mathrm{cm}$ wide by $0.018 \mathrm{~cm}$ th1ck] soldered between two copper plates (Figure 27 above). This specific coil design uses only two discrete lengths of conductor, $4.3 \mathrm{~m}$ for the shorter sides and $7.7 \mathrm{~m}$ for the longer sides. Using current commerctal values of $\mathrm{Jc}=2 \times 10^{5} \mathrm{~A} / \mathrm{cm}^{2}$ at 12 Tesla and allowing a $50 \%$ safety factor, a total cross sectional area of $1.5 \mathrm{~cm}^{2}$ was allotted for the superconductor. 


\section{FIG. 28, COIL AND CONDUCTOR DESIGN SHOWING -DETAILS OF CON- DUCTOR ASSEMBLY, CERAMIC INTER-TURN INSULATORS AND POOL BOILING LIQUID CONCEPT}

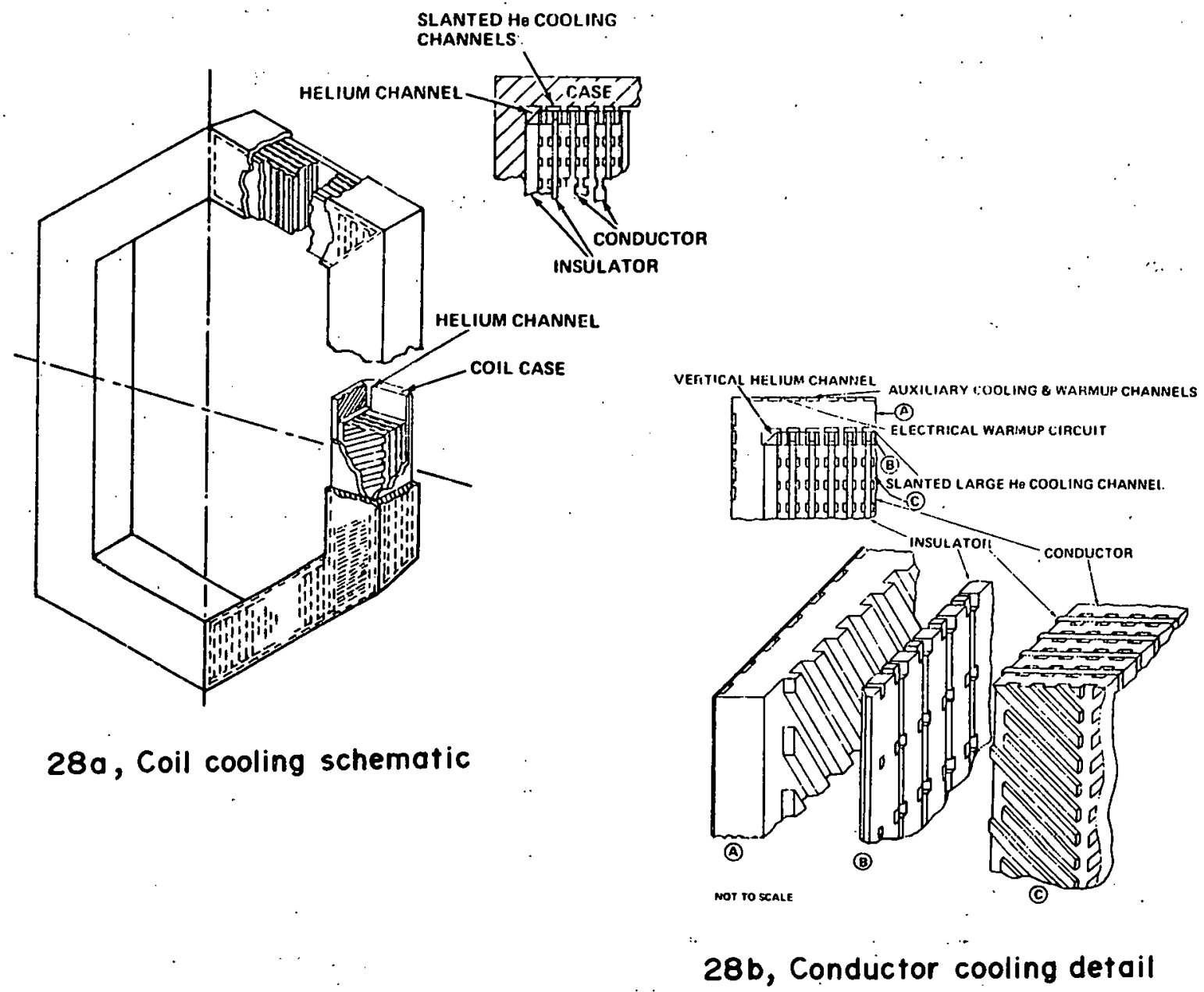

Cooling grooves on the conductor surfaces [width $4 \mathrm{~mm}$ and depth $0.76 \mathrm{~mm}$ ] expose $50 \%$ of the surface to helium 1iquid for cooling, and result in a cooling surface of $11,430 \mathrm{~cm}^{2}$ per meter length of conductor. If the entire current of 200,000 A flows in the copper, the heat flux to He is $0.38 \mathrm{w} / \mathrm{cm}^{2}$, for a conservative estimate of $6.5 \times 10^{-8} \Omega \mathrm{cm}$ for the resistivity at 12 Tesla. For these wcrst possible operating conditions, the heat flux is well within the limits of cryostability for the system. A lower average value of copper 
resistivity would be more realistic since most of the copper is at a lower magnetic field than $12 \mathrm{~T}$, but the higher value gives an added safety margin. The cooling grooves are slanted at an angle of $25^{\circ}$ to the vertical in the vertical coil segments and are vertical in the sloping top and bottom sections as shown in Figure 19. Thus helium bubbles formed at the conductor surface never travel more than one meter before they are vented through the side insulation to large helium channels in the inner wall of the coil case (see Figure 28b).

The coil design parameters are shown in Table 7. Where possible, they were chosen comparable to those used in large bubble chamber magnets, because of their demonstrated success, and rellability in the use of cryostable conductors with pool boiling liquid helium. Recently, a number of proposals

\section{TABLE 7, HFITR COIL. DESIGN PARAMETERS}

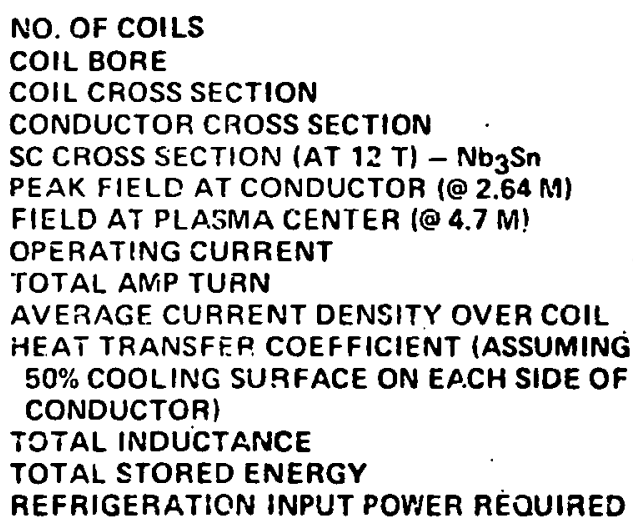

16

$5 \mathrm{M} \times 8 \mathrm{M}$

$0.85 \mathrm{M} \times 0.567 \mathrm{M}$

$8 \mathrm{~mm} \times 0.8 \mathrm{M}$

$-1.5 \mathrm{~cm}^{2}$

$12 T$

$6.8 \mathrm{r}$

$2 \times 10^{5}$ AMP

$1.6 \times 10^{8}$

$-2140 \mathrm{~A} / \mathrm{cm}^{2}$

$0.38 \mathrm{~W} / \mathrm{cm}^{2}$

$-1 \mathrm{H}$

$=2 \times 10^{10} \mathrm{~J}$

1.65 MIN (ROOM TEMP)

$4.47 \mathrm{KW}\left(\mathrm{AT} 5^{\circ} \mathrm{K}\right)$ 
Involving magnet cooling by forced convective flow have appeared. Such cooling systems could be used in DEALS magnet systems if desired. These forced cooling systems increase the heat transfer rates for cryostable operation and hence reduce conductor size and weight while simplifying coil fabrication. The risk of helium pump failure has to be reduced to acceptable levels before such a system can be considered for large scale use. However, the promise of reduced size and cost will provide ever growing pressure to use such systems in future years.

B. Observations on Supercritical Helium Forced Cooling for DEALS Magnets

The behavior of liquid helium used in the pool boiling mode has been studied for many years: Magnet designs vary in the value they choose for the magnitude of the maximum heat $\mathrm{flux}\left(\mathrm{w} / \mathrm{cm}^{2}\right)$ which flows across the boundary between the helium and the surface being cooled. To some extent this reflects the degree of conservation demanded by specific engineering requirements imposed by case rellability and magnet size and field intensity. Some degree of personal judgment is involved. Effective heat transfer ceases when the film boiling point is reached. These considerations determine the amount of copper or other stabilizer which is specified in a superconducting system. The Joule heating in the normal conductor divided by the cooled surface area should not exceed the maximum heat flux value chosen. If supercritical hellum cooling is chosen, no similar maximum heat flux exists. The actual magnitude of the tolerable heat flux in this case is determined by such quantities as the temperature differential between coolant and conductor $(\Delta T)$ and the rate of flow of coolant. 


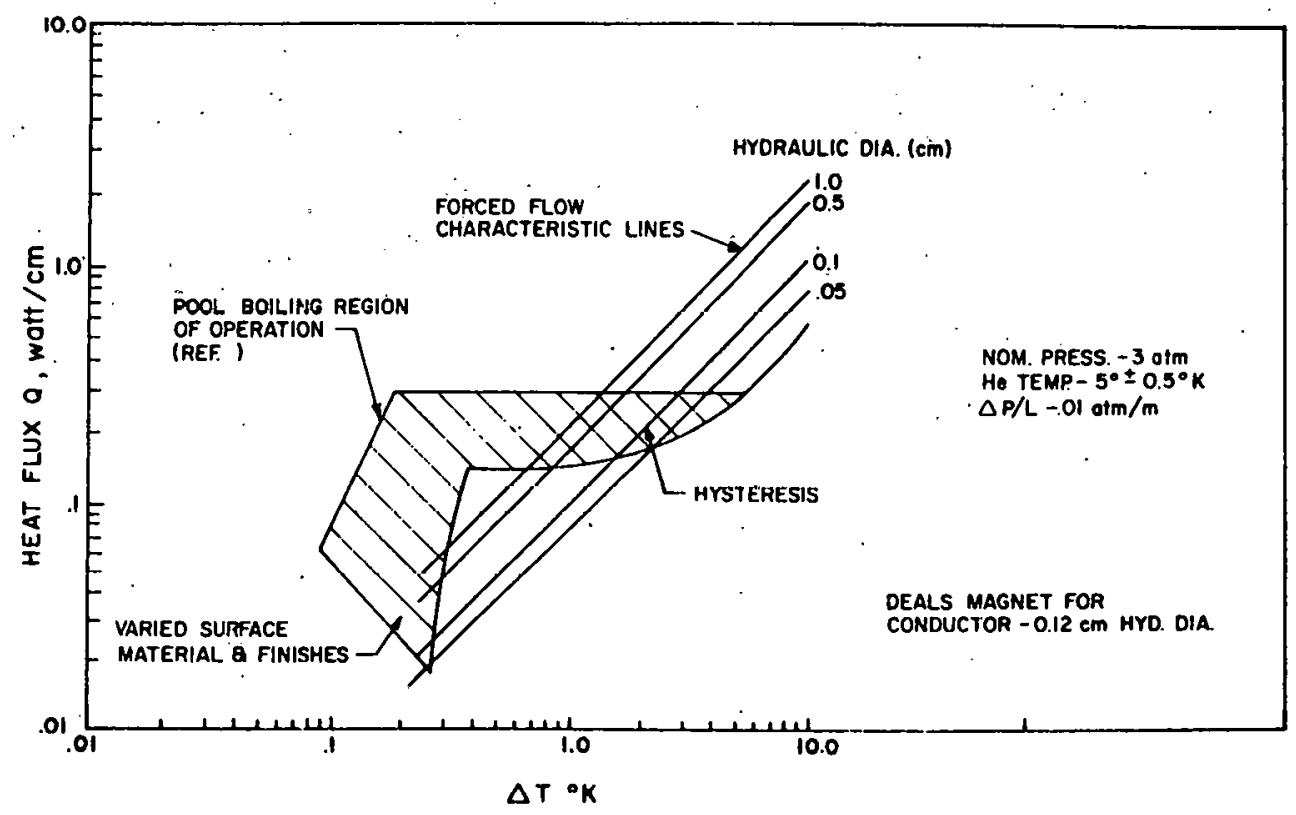

FIG. 29, COMPARISON OF POOL AND FORCED FLOW CAPABILITY

A comparison of the best current judgment on tolerable pool boiling heat transfer rate with forced convective flow is shown in Figure 29 for the configuration presented in the pool boiling DEALS magnet study. No attempt has been made at this stage to optimize the conductor for the forced flow case since the question of pool boiling versus forced flow cooling is not crucial to the success or failure of the DEALS concept. Some conclusions which can be drawn from the data of Figure 29 are as follows:

1. Where $\Delta \mathrm{T}$ is small $\left(\sim 1^{\circ} \mathrm{K}\right)$ between He and the conductor to be cooled, the largest heat flux is obtained with pool boiling. 'Thus, pool boiling is attractive for cooling $\mathrm{NbTi}$ when the critical temperature is less than 1 degree above the liquid temperature. 
Equations Used to Derive the Forced Flow Supercritical Helium Cooling Characteristic Durves of Figure 29

$$
\begin{aligned}
& \text { h. }=B\left(\frac{\Delta \mathrm{P}}{\mathrm{L}}\right)^{0.44} \mathrm{D}^{0.33} \\
& \text { B }=\left(\frac{\mathrm{k}^{6} c_{\mathrm{p}}^{3} \rho^{4}}{\mu^{5}}\right)^{0.11} \cdot 2.027 \\
& \frac{Q_{p}}{L}=\quad=\quad \cdot A_{f} \cdot\left(\frac{\Delta P}{L}\right)^{1.56} \cdot D^{0.67} \\
& \text { c } \quad=\left(\mu \rho^{4}\right)^{-0.11} \times 31.71 \\
& \frac{Q_{p}}{Q_{n} / \Delta T}=\frac{c}{4 B}\left(\frac{\Delta P}{L}\right)^{1.11} D^{1.33}
\end{aligned}
$$

h Heat transfer coefficient, watt $/ \mathrm{cm}^{2}{ }^{\circ} \mathrm{K}$

$\Delta \mathrm{P} \quad$ Coolant channel pressure drop, atmospheres

L Channel length, meters

D Channel hydraulic diameter, $\mathrm{cm}$

$\mathrm{K}$ Thermal conductivity, watts/cm ${ }^{\circ} \mathrm{K}$

$c_{p}$ Specific heat, watt sec/gm. $\mathrm{K}$

$\mu \quad$ Viscosity, $\mathrm{gm} / \mathrm{cm} \mathrm{sec}$

$\rho$ Density, $\mathrm{gm} / \mathrm{cm}^{3}$

$A_{f}$ Channel flow area, $\mathrm{cm}^{2}$

$\Delta \mathrm{T}$ Metal to hellum temperature difference, $\mathrm{K}$ 
2. Where $\Delta T$ is large (say $5-10^{\circ} \mathrm{K}$ ) a heat flux much in excess of the maximum pool bolling value can be obtained using supercritical gas cooling.

3. Using the characteristic curves derived for forced flow cooling from the equations listed in Table 4, we can see that use of forced flow cooling offers the possibility of Increasing $\Delta T$, the operating temperature differential between conductor and bath, and hence the operating heat flux for a given degree of cryostability, assuming that a superconductor such as $\mathrm{Nb}_{3} \mathrm{Sn}$ with an acceptable critical temperature for the fleld intensities and superconductor current densities are used. In turn, this could reduce considerably the amount of stabilizer needed, and hence conductor size and cost. As an example, FIgure 21 shows that use of a $0.12 \mathrm{~cm}$ diameter channel with a $\Delta T$ of $5^{\circ} \mathrm{K}$ would Increase the working heat transfer coefficlent for the DEALS conductor chosen in this study by about 40 percent with a consequent reduction In the copper stabilizer requirement. An additional feature of this type of cooling, which is not possible with pool boiling, is that the operating heat flux can be increased if desired, to improve the margin of safety, by increasing the coolant flow rate. This would increase pumping losses and refrigeration load, and would only be feasible if adequate reserve capacity was chosen in the refrigeration system.

\section{Heat Load Estimation and Refrigeration Requirements}

The heat loading calculations have been described elsewhere. The results are listed in Table 9.

The heat load created by the instrumentation leads is developed using the same criterla as before ${ }^{1}$ for the 16 coil system, and represents $40 \mathrm{~kW}$ of room temperature refrigeration power. The heat load due to the 31 coil case support 


\section{TABLE 9, REFRIGERATOR INPUT POWER REQUIREMENTS}

\author{
EDDY CURRENT (300 SEC CYCLE, NO SHIELDING) \\ HYSTERESIS (300 SEC CYCLE, NO SHIEI.DING) \\ CONDUCTOR JOINTS (50\% CONTACT AREA) \\ POWER LEADS - 16 COILS IN SERIES \\ INSTRUMENTATION LEADS \\ COIL CASE SUPPORTS \\ VACUUM DEWAR LOSSES
}

\author{
ROOM TEMP. POWER, MW \\ 0.20 \\ 0.06 \\ 0.32 \\ 0.58 \\ 0.04 \\ 0.23 \\ 0.02 \\ TOTAL $=\overline{\mathbf{1 . 4 5}} \mathrm{MW}$ (ROOM TEMP.) \\ $=4.47 \mathrm{KW}$ (AT $\left.\mathrm{S}^{\circ} \mathrm{K}\right)$
}

pads is estimated from the $20^{\circ} \mathrm{K}$ heat station to a $4^{\circ} \mathrm{K}$ environment to require $230 \mathrm{~kW}$ of refrigerator input power. The vacuum dewar loss from the $80^{\circ} \mathrm{K}$ radiation shield to the $4^{\circ} \mathrm{K}$ environment was estimated to require $20 \mathrm{~kW}$ of refrigerator input power.

1. Poẉer Leads

One pair of input power leads from the room temperature environment to helium temperature can be used, if the 16 coils of the magnet system are connected in series. The refrigeration for this pair of leads would require $0.58 \mathrm{MW}$ of refrigerator input power. The low, one Henry inductance of the magnet system, a result of the small number of turns, makes the series convection option feasible. If there is $2,000 \mathrm{~V}$ allowed between coil and ground, the . coil energy can be dumped externally in less than 100 seconds. As shown by Table 9, the heat load due to the power leads could be absorbed by the cold hellum return gas, if all the hellum vaporized by the other heat inputs to the magnet is returned to room temperature through the power leads. 
FIG. 30, A.FAIL-SAFE POWER LEAD FOR SUPERCONDUCTING COILS
FIG. 3I, A LOS ALAMOS SCIENTIFIC LABORATORY PRESSURE CONTACT JOINT
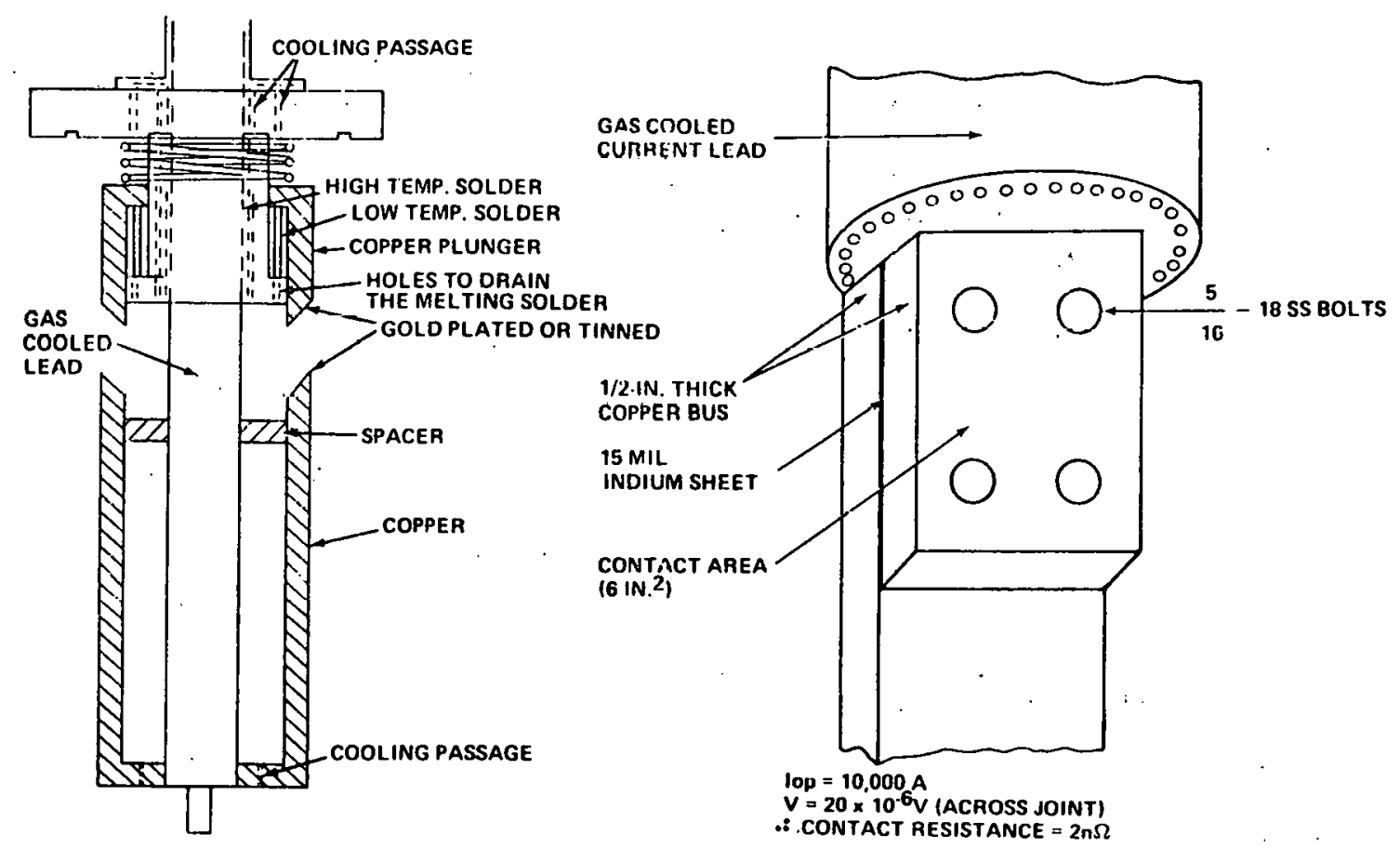

A fail-safe power lead of improved reliability is shown in Figure 30 . It is designed ${ }^{3}$ to provide a current bypass in fault conditions so that the magnet operation will not be interrupted due to power lead failure. Development of such power leads would require a laboratory test program.

2. Conductor Joints

Pressure contacts have been adopted for this design because the passive support system which restrain the magnet conductors require movable joints. Otherwịse, conductor strain would be excessive. Both soldered joints and pressure joints have been successfully used in low temperature superconducting magnets. For example, the banana plug type sliding joint for low temperature application works successfully in LASL'S energy storage system. ${ }^{6}$ (See Figure 31. ) 


\section{FIG. 32, CONTACT HEATING vS. COPPER RESISTIVITY AND EFFECTIVE}

CONTACT AREA

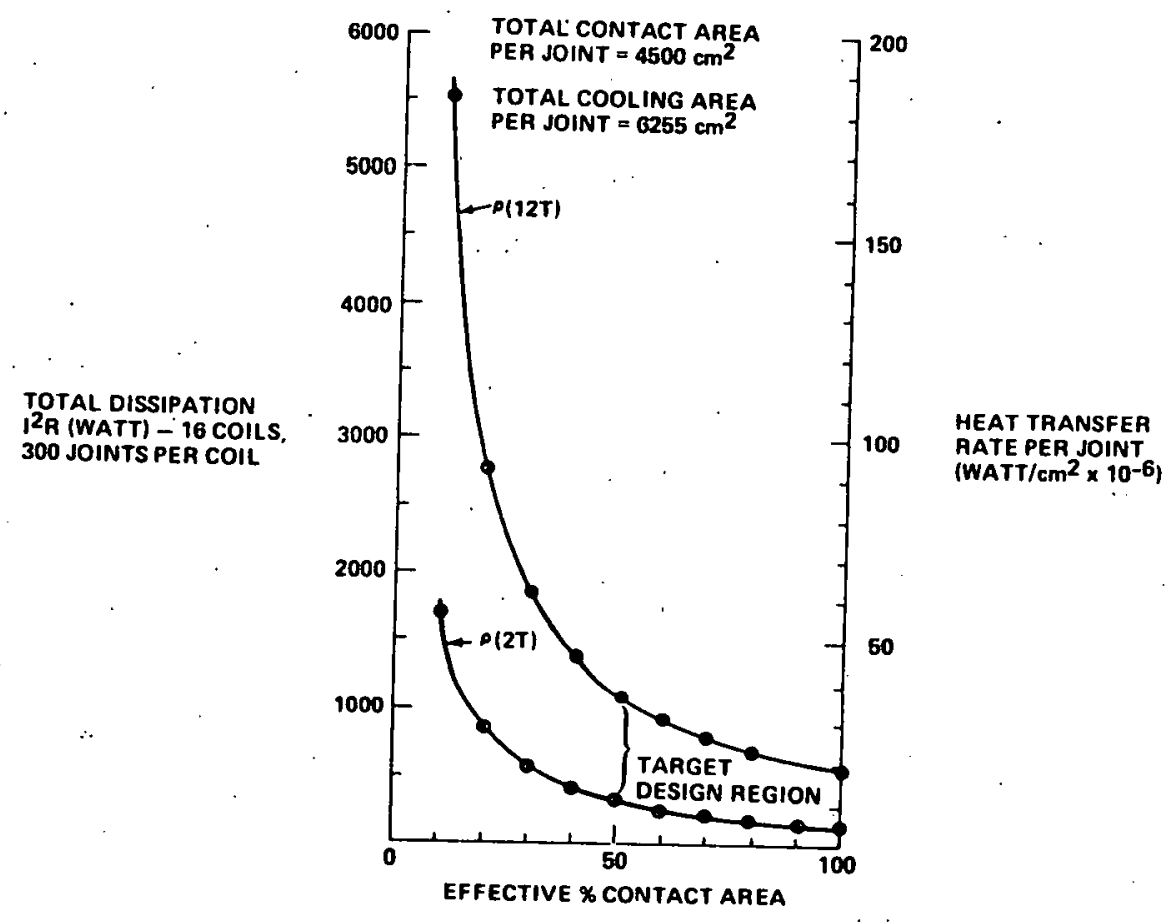

However, the movable pressure joints needed in this spectfic DEALs system magnet design have yet to be developed experimentally. The variation of power dissipation with effective contact area for a single joint and the total system was calculated for values of copper resistivity at maximum magnetic field and 2 Tesla (see Figure 32). Assuming that $50 \%$ of the $4,500 \mathrm{~cm}^{2}$ is effective, the ohmic heating at the joint area is estimated to be approximately $1 \mathrm{~kW}$ (Ffgure 32). It should be emphasized that the passive magnet support system approach depends on the sultability of this type of conductor joint. The development of such contact joints will require a comprehensive and well structured experimental program. 


\section{FIG. 33, CONCEPTUAL JOINT DESIGN'S CLEARANCE TAKE UP COMPRESSION OPTIONS}

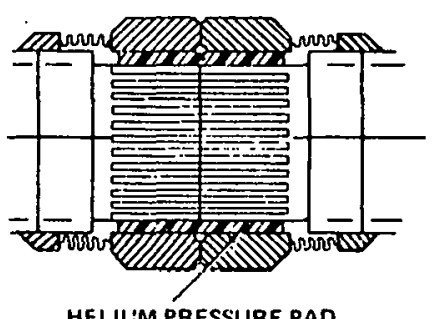

HELIUM PRESSURE PAD

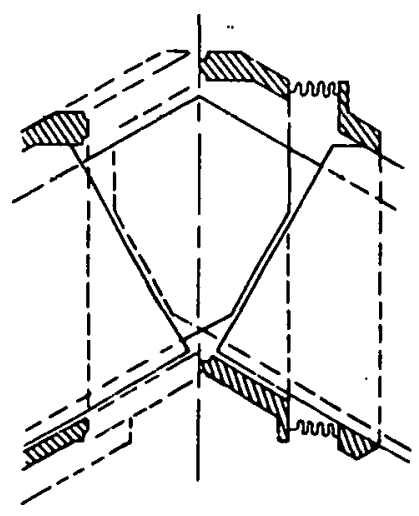

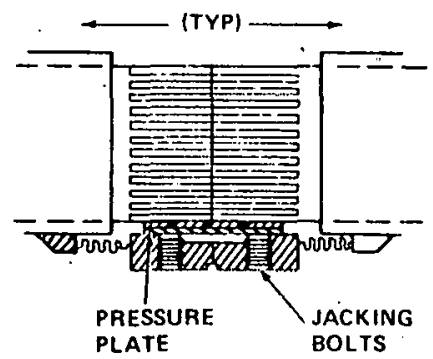

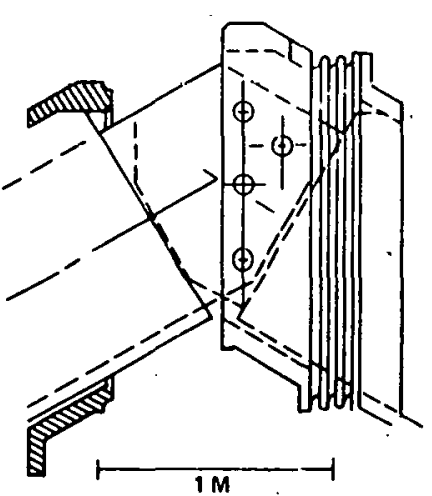

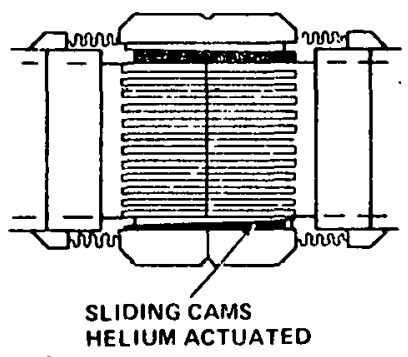



D. Mechanical Design of Conductor Joints

The mechanical design of the conductor joints and conductor stresses during cool down and operation requires knowledge of the clamping pressure, working area and effective coefficients of friction. This information can only be derived from an experimental program. In the absence of such information, conceptual studies of the joints and identification of key design issues have been made. The design must first allow for ample clearance between a11 the components of the joint during assembly. It must then apply clamping pressure after assembly and cool down. The conceptual design options considered for this study are illustrated in Figure 33. Their key features are as follows:

1. The interconnections between conductors are made by interleaving copper conductors at the joint. 
2. An electrical comection technique, as yet unspecified, is assumed to provide a sultably low reslstance junction between corresponding conductor leaves. Each connection Junction is electrically insulated from adfacent junctions by plates of ceramic insulation, which are radiation resistant.

3. The joint region is surrounded by slip-away joint collars. These are retracted during assembly to provide complete access to the joint. They are then pulled up after assembly, and welded to each other and the conductor cases.

4. The joint collars contain bellows to allow for thermal and load induced movements.

5. Some type of clearance take up and joint compression device is located between collar and fingers.

The option shown in Figure 33a uses flat hollow stainless steel pressure pads filled with liquid helium. Their position can be adjusted by varying the pressure of the internal liquid helium. With this concept, pressure can be relieved during cool down to allow the plates to move freely relative to each other. During operation, the clamping pressure can be adjusted to desired levels. The liquid helium compressibility might possibly allow the joints to move out of plane under some load conditions. In the design of Figure 24b, take up and compression are adjusted at room temperature by means of jacking bolts. This froduces a desirably stiff joint, but cool down shrinkage occurs in the locked joint and contact pressure has to be fixed at room temperature. The design of Figure $33 \mathrm{c}$ retains the advantages of Figures $33 \mathrm{a}$ and $33 \mathrm{~b}$. In this case, sliding cams are actuated by liquid helfum so that it has the stiffness of a mechanically locked joint; while at the same time, the contact pressure can' be adjusted. More study would be required to choose the most destrable approach. 


\section{CONTACT TESTS}

\section{A. Introduction}

The previous section included a discussion of the contact problem from the point of view of some theoretical considerations and some Los Alamos Scientific Laboratory experience. It was concluded that the problem was soluble and that no fundamental obstacles lay ahead: However, a serious. engineering technology development program is required to develop a practical solution to the problem. The cost and time scale for such a study exceeds the time and resources available for the present work. Attempts to assess the magnitude of the experimental problem were started by developing a test rig for simulating the performance of movable contacts on a small scale and by carrying out some additional rough tests in liquid helium using improvised contacts and available test equipment.

\section{B. Object of Tests}

The object of the tests was to obtain a general feeling for the problems involved in operating contacts which creep slowly due to contraction on cool down to helium temperature and then rotate slowly with respect to each other as the magnet current is increased to its maximum operating value. Movements of about $1 \mathrm{~cm}$ are estimated to be involved in both the creep and rotation at the contacts of each winding for the reactor investigated in this study (open bore of the mignets is $5.5 \times 7.5$ meters).

The conductor current for the conceptual design under study is $200 \mathrm{kA}$ and it is transmitted from segment to segment of the winding through a contact of surface area $4,500 \mathrm{~cm}^{2}$ anticipated, for the sake of argument, tc be about $50 \%$ efficient (1.e., to have an effective contact area of $2250 \mathrm{~cm}^{2}$ ). This corresponds to a current transfer del sity of $88.9 \mathrm{~A} / \mathrm{cm}^{2}$. This question of effective contact area for such large plates has to be resolved, as has the question of adequate contact pressure and choice of contact materfal. 
FIG. 34, TEST RIG FOR SIMULATING MOVABLE CONTACTS

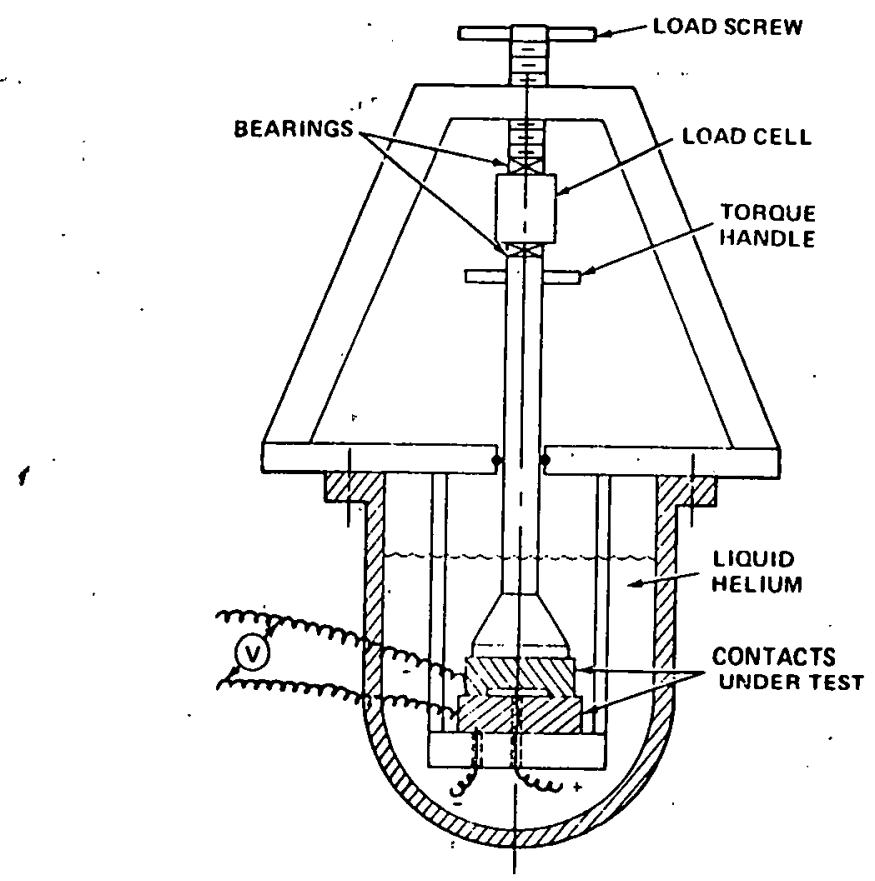

C. Small Scale Test Rig

The small scale test rig is shown in Figure 34. It permits testing at various pressures and current densities, using small areas of contact surface which can be changed as desired, either by changing the contact size or material type. Surface conditions between the contacting surfaces can also be changed. Tests will be carried out at rocm temperature, in liquid nitrogen or in liquid helium as desired. So far, only room temperature tests between copper surfaces have been carried out. Under such cnnditinns, the oxide layer which forms on the copfer leads to poor and varying contacts as might be expected. However, it must be re-emphasized that this work has just started, and is currently at a very low level of effort. At least the tests serve to show that the test rig works in a satisfactory way to develop the information we require. 


\section{Scoping Tests in Liquid Helium}

As an interim measure, while the precision small scale test rig was being designed and constructed, it was decided to scope the problem by improvising a simple test rig to utilize exlsting test equipment and to work in liquid helium at currents up to $5000 \mathrm{~A}$ in the event that problems of scale were a factor. Extrapolation from 5 to $200 \mathrm{kA}$ is less than two orders of magnitude, and in a reasonably practical high current range to increase confidence in prediction of possible performance at the high currents. The precision rig was designed for comparable current transfer densities but much lower currents.

A precision rig had been developed in the BNL ISABELLE project superconducting group for holding and testing diode protection elements at helium temperature. This rig was designed to hold and clamp a copper specimen of dimenstons $2 \mathrm{~cm} \times 2 \mathrm{~cm} \times 1 \mathrm{~m}$ thick at a load of about $1500 \mathrm{lbs}$ and to apply currents of up to 5000 A through niobium-tin input power leads at liquid helium temperature (see Figure 35). By twisting the room temperature ends of the power leads, it was possible to slide the contact about $1 \mathrm{~cm}$. The variation of voltage drop with current was measured with the contacts untouched after cooling to helium temperature and then repeated after each twist of the contacts through the $1 \mathrm{~cm}$ travel. The current through the square sample for a contact transfer current density of $89 \mathrm{~A} / \mathrm{cm}^{2}$ was $356 \mathrm{~A}$. In later tests, an annular cylindrical OFHC copper sample of $10 \mathrm{~cm}^{2}$ contact area was used. At the $900 \mathrm{~A}$ of contact transfer current through the discs would correspond to the conditions of use. 


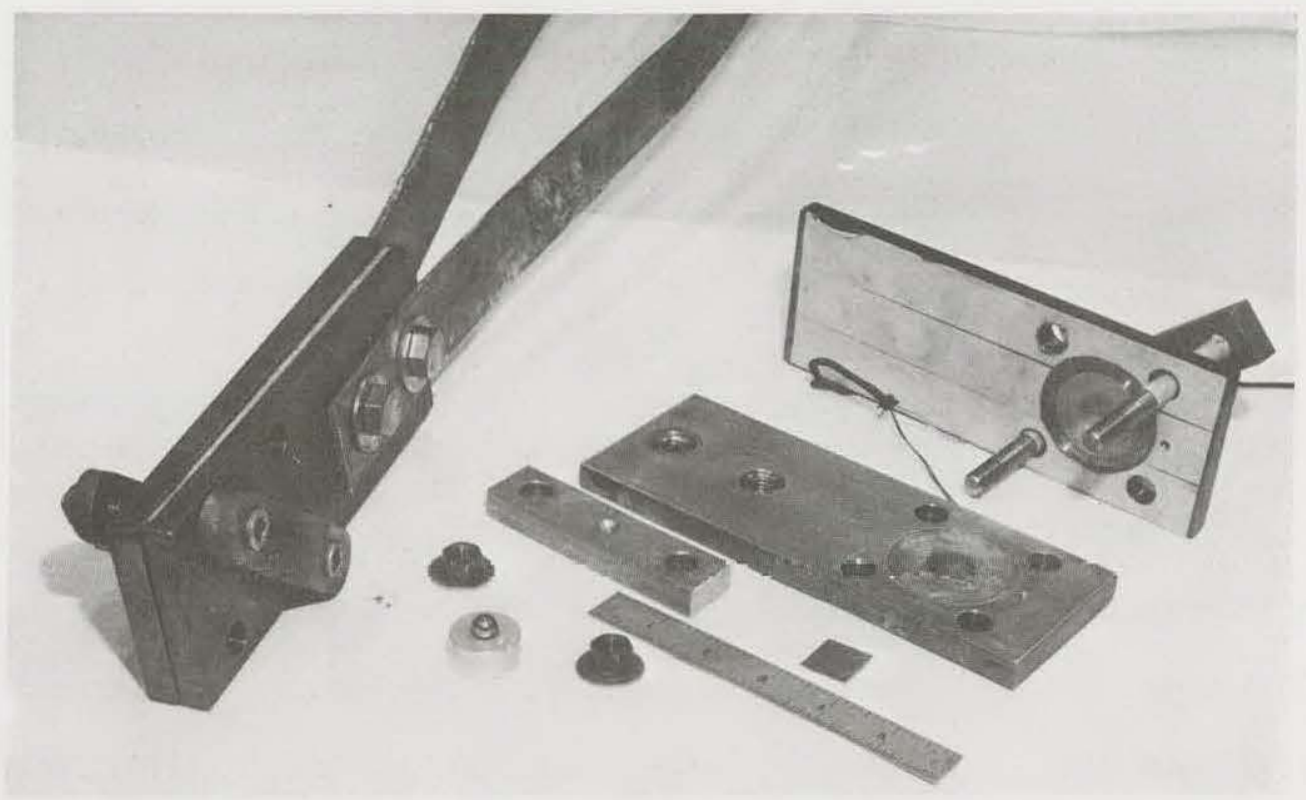

FIG. 35, ARRANGEMENT FOR ROUGH SCOPING TESTS OF CONTACTS IN LIQUID NITROGEN AND HELIUM AT UP TO 5000 A

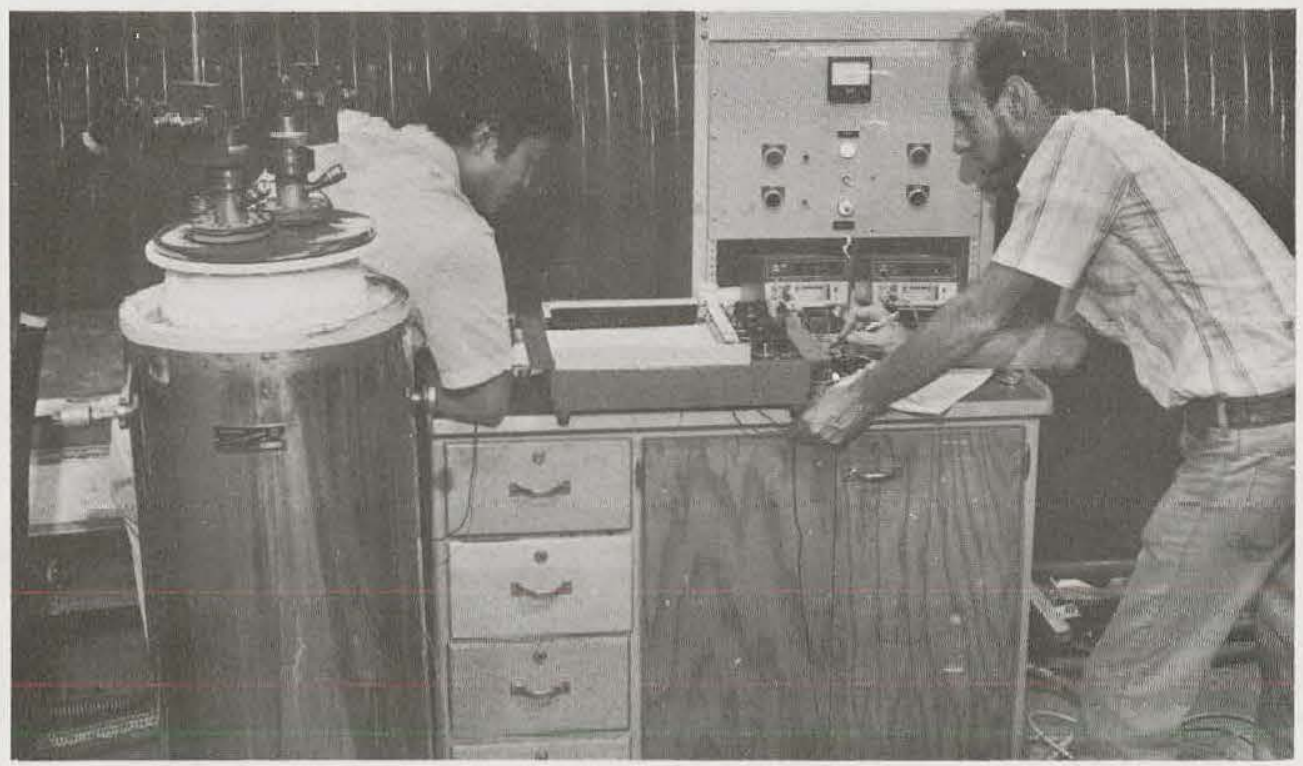

FIG. 36, TEST INSTALLATION FOR SCOPING TESTS ON CONTACTS AT LIQUID HELIUM TEMPERATURES 


\section{E. Qualitative Impressions from Scoping Tests}

1. $2 \mathrm{~cm}$ square $1 \mathrm{~mm}$ thick specimens

In the rough tests with the $2 \mathrm{~cm}, 1 \mathrm{~mm}$ thick copper disc compresses between the plates (see Figure 35). It was found that there was a considerable variation In measured contact resistance from test to test when the pressure to the clamping plates was applied by means of a spiral spring of known spring constant. This was due to the indeterminacy of the pressure applied to specimen itself, presumably due to buckling of the clamping plates, stress redistribution on cool down and minute variation in plate flatness. Spring tensions of between 100 lbs and $2600 \mathrm{lbs}$ were used in the various tests at room temperature, liquid nitrogen temperature and liquid helfum temperature. Thermal cycling had little effect on contact resistance at the higher pressures while increases from 2000 to 2600 lbs caused measured increases in contact resistance presumably due to increased buckling of the clamping plates and possible reductions in current transfer area or pressure at the specimen. The use of silvered surfaces had little effect in these tests. At pressures of $2001 \mathrm{bs}$ (1.e., $227 \mathrm{kgm} / \mathrm{cm}^{2}$ ) we were unable to rotate the contacts with this test arrangement. When the pressure was reduced by a factor of 10 , it was possible to rotate the contacts but surface scoring occurred, possibly due to point to point cold welding at the higher pressure and the contact corductance degraded by orders of magnitude. While these scoping investigations were under way a heavier annular type disc was prepared to avoid some of the problems highlighted above and tests were continued with the arrangement.

\section{Annular Disc Specimen}

In an attempt to apply pressure in a more controlled way and to use a stronger, more direct method for rotating the contacts a $13 / 4$ inch o.d., 
1 inch 1.d., center tube of OFHC copper was used with a disc like specimen on either side. Rotation of the contact was effected by means of a mild steel rod threaded into the tube and operated as a lever. The annular contact area was approximately $10 \mathrm{~cm}^{2}$. The spring pressure of $20001 \mathrm{bs}$ was equivalent to a joint pressure of $1230 \mathrm{psi}$. At this pressure in liquid helium, the contacts could not be rotated without damaging the lever. The pressure was gradually reduced and attempts were made to rotate the contacts at each pressure. Only at zero pressure could the contact be rotated. The rotation then resulted in scoring of the surface. Pressures of around 2000 1bs resulted in contact resistances of about $1.8 \times 10^{-8}$ ohms in these rough tests and the use of silvered surfaces did not materially affect the results. Again at the lower pressure, with rotation of the contacts, the contact resistance degraded considerably due to scoring of the surfaces and reduced contact area.

In conclusion, we were able to assess from these tests that a serious, long term, well structured experimental program using well engineered test contacts is necessary to develop an adequate engineering solution to the contact problem. However, even in these tests it was possible to approach values of contact resistance which at best were comparable with those accepted in engineered devices elsewhere. 


\section{Acknowledgments}

We thank D. Jassby, J. File, and M. Okabayashi of Princeton Plasma Physics Laboratory for their assistance and encouragment. The contact tests in liquid helium were carried out with the assistance of BNL ISABELLE Project staff of the Superconductivity Group; in particular, W. Sampson, and K. Robins. Planning for the longer range contact tests involved A. Prodell and G. Danby of BNL's AGS Division. The assistance of the BNL Design Group under Stan Majeski, in preparing the figures and Grumman Aerospace, and Carolyn Eterno and Pam Walton in providing essential typing and secretarial help, is gratefully acknowledged. 